\title{
ELASTIC CRITICAL MOMENT FOR BISYMMETRIC STEEL PROFILES AND ITS SENSITIVITY BY THE FINITE DIFFERENCE METHOD
}

\author{
M. KAMIŃSKI* and Ł. SUPEŁ \\ Department of Structural Mechanics \\ Faculty of Civil Engineering \\ Architecture and Environmental Engineering \\ Al. Politechniki 6, 90-924 Łódź, POLAND \\ E-mail: marcin.kaminski@p.lodz.pl \\ lukasz.supel@p.lodz.pl
}

\begin{abstract}
It is widely known that lateral-torsional buckling of a member under bending and warping restraints of its cross-sections in the steel structures are crucial for estimation of their safety and durability. Although engineering codes for steel and aluminum structures support the designer with the additional analytical expressions depending even on the boundary conditions and internal forces diagrams, one may apply alternatively the traditional Finite Element or Finite Difference Methods (FEM, FDM) to determine the so-called critical moment representing this phenomenon. The principal purpose of this work is to compare three different ways of determination of critical moment, also in the context of structural sensitivity analysis with respect to the structural element length. Sensitivity gradients are determined by the use of both analytical and the central finite difference scheme here and contrasted also for analytical, FEM as well as FDM approaches. Computational study is provided for the entire family of the steel I- and $\mathrm{H}$ - beams available for the practitioners in this area, and is a basis for further stochastic reliability analysis as well as durability prediction including possible corrosion progress.
\end{abstract}

Key words critical moment, Finite Difference Method, sensitivity analysis, thin walled structures, Finite Element Method.

\section{Introduction}

Elastic stability phenomenon of a beam has been studied and developed in totally different contexts and models for more than two centuries. Trahair $[1 ; 2]$ presented a complete and general state of knowledge on the elastic lateral-torsional buckling and strengths of the laterally unsupported beams after pioneering works of Leonhard Euler explored in many existing engineering designing codes. He presented introductory and very important studies of the analytical analysis of the issues described also in Trahair [1], Bleich [3], Chen and Atsuta [4], Galambos [5], Timoshenko and Gere [6], Vlasov [7], and outlined the areas of unexplored or incomplete knowledge, necessary to be developed in the nearest future. Nowadays, the literature related to the elastic lateral-torsional buckling focuses on numerical methods for the critical moment approximate estimation rather, and the influence of an additional restraints against warping at the ends of the beam as well as against the translation along its span. Lam et al. [8], for instance, presented an investigation concerning the lateral-torsional buckling resistance of the coped beams. They studied how the coped ends affect the overall reduction of the bending and torsional stiffness of a beam - local instability of the tee-section at the supports does not reduce the overall lateral-torsional buckling resistance for the very short copes, but these copes affect the boundary condition. Masarira [9] implemented numerical study to investigate an influence of the joint construction on the lateral-torsional behavior of steel frames. This warping can be assumed fully prevented for the beam-to-column connection with an internal extended flanges or with the additional diagonal stiffening. A very similar study was also carried

\footnotetext{
* To whom correspondence should be addressed
} 
out by Tong et al. [10] - they investigated warping and bimoment transfer through the beam-to-column connection by using the Finite Element Method. Further, Larue et al. [11] presented a simple model of an elastic buckling of the beam with rigid and continuous lateral restraint of its upper flange. They developed a numerical procedure for resolving the additional partial differential equations, where rotational displacement along the span is approximated by the relevant trigonometric function. Their method renders it possible to propose a formula for the critical moment calculation alternative to this developed in most popular recent design code procedures (EC3, AISC LFRD, BS-5950, SN003a-EN-EU [12]), which is valid for different cases of the external loadings; these authors conclude controversially, contrary to a common knowledge, that the lateral restraint does not increase significantly the critical buckling moment. Serna et al. [13] presented a review study devoted to the equivalent uniform moment factors for the lateraltorsional buckling. This review stated clearly that there is enough information in literature and in commonly used design code procedures for the beams with fully restrained bending and twisting at the supports, but these with no restrained warping (so-called fork support) still needs some attention. There is a very good agreement between the values obtained from the design procedures and, independently, for the numerical results in case of the simply supported beams. In contrast, the design rules do not adequately address the issue when warping is prevented (this is also confirmed in a comparative study provided in this work). In most cases warping prevention leads to the overshooting of the critical moment, how it is demonstrated also below. These authors used for computational analysis two different numerical methods - the Finite Difference and Finite Element Method. Nguyen et al. [14], [15] studied the lateral-torsional buckling resistance of I-girders with the discrete torsional bracings at the mid-span. The equivalent continuous brace stiffness concept has been adopted for a general discrete torsional bracing issue, and the analytical solution obtained has been compared with the critical moment and torsional stiffness requirements derived from the energy method for an assumed number of the restrained points. Finally, Park et al. [16] considered buckling resistance of the beams with the upper flange braced against any deformation by some metal (preferably steel) or the reinforced-concrete plate structure. These authors used the Finite Element Method to analyze the critical moment for the beams under concentrated or the uniformly distributed loading; this elaboration includes a review of the moment gradient factors from the design code procedures also.

The critical moment value is of crucial significance for an estimation of the lateral-torsional buckling resistance of a structure subjected to combined bending and torsion in its plane of major stiffness. The well-known formulas derived analytically for a critical moment are valid for the specific cases of both supporting and loading conditions of a beam (especially efficient for the simply supported beam). The calculation procedure of the elastic critical moment can be carried out numerically for more complex support and loading conditions (allowing very realistic elastic supports also). Various popular numerical methods can be employed for this purpose including the Finite Element Method (FEM) (Bathe [17], Zienkiewicz and Taylor [18]), which involves the additional approximation of the shape functions as well as the Finite Difference Method (FDM) (Liszka and Orkisz [19], Mitchell and Griffiths [20], Wasow and Forsythe [21]), which involves the approximation of the individual terms of the differential equation. The basic difference in-between these methods is that the FEM usually needs the entire larger set of various computational routines, so that a modification of the existing program to include the new procedure like determination of the critical moment may demand a direct access to the source code, which is not always possible. The FDM implementation is totally straightforward - practically it is enough to have some symbolic algebra program, where the difference operators can be defined together with regular, even very dense, discretization, and where according to matrix operations and the implemented eigenproblem solution methods such an extension is relatively easy even for non-experienced programmers and civil engineers. Therefore, the Finite Difference Method implementation in the symbolic algebra program MAPLE Char [22] has been presented in this paper and its results of the critical moment calculation have been compared to results obtained from both analytical formula and the Finite Element Method. The usefulness and accuracy of the numerical results for the employed numerical method can be estimated by a comparative study for the single-bay steel beam having elementary loading and supporting conditions (like simple support or the both edges being fully restrained, while these adjacent to the cantilevers may be 
found in Zhang and Tong [23] and for a variety of steel profiles belonging to three families of bisymmetrical I profiles, namely HEB, HEA and IPE; this is done to discover principal differences in practical applications of these shapes in civil engineering. We use further all these methods to determine sensitivity coefficients of the critical moment with respect to the major design parameter - the length of the element for the same wide range of steel profiles available on the market to give some guidelines for most efficient optimization of the beams cross-sections; it follows an idea demonstrated briefly by Suryoatmono and Ho [24]. This comparative studies and development of the Finite Difference Method computer program is the first step towards future reliability analysis and durability prediction of the steel girders subjected to random fluctuations of their parameters, stochastic corrosion and/or fatigue processes demanded by the modern steel designing codes and procedures.

\section{Exact solution of a critical moment of laterally unrestrained beam subjected to pure bending}

The elastic critical moment is given by the exact solution derived from the buckling theory represented by Eq.(2.1) for laterally unrestrained and simply supported beam of bisymmetric cross-section, loaded at endpoints with two concentrated moments, equal and opposite to each other. Such a beam is subjected also to the constant bending moment and its compressed flange is free to displace laterally and also rotate. The buckling resistance for a section subjected to pure bending is less than the buckling resistance obtained for the same section subjected to any different bending moment distribution, therefore an approach for critical moment calculation with assumed a constant moment is conservative. Figure 1 shows the beam loading and supporting condition, and the lateral and rotational displacements of a beam when lateral torsional buckling occurs. For the proposed analysis an influence of local and distortional buckling is neglected, and hence interaction between local, distortional and overall modes of buckling is neglected as well. The structural members satisfy all the assumptions of the Vlasov theory for the thinwalled sections (Vlasov [7]). Despite the flanges and the web are thin-walled plates, the shape of the cross-section is not changing under any loading (the distortional deformation of the cross-section is restrained).

a)

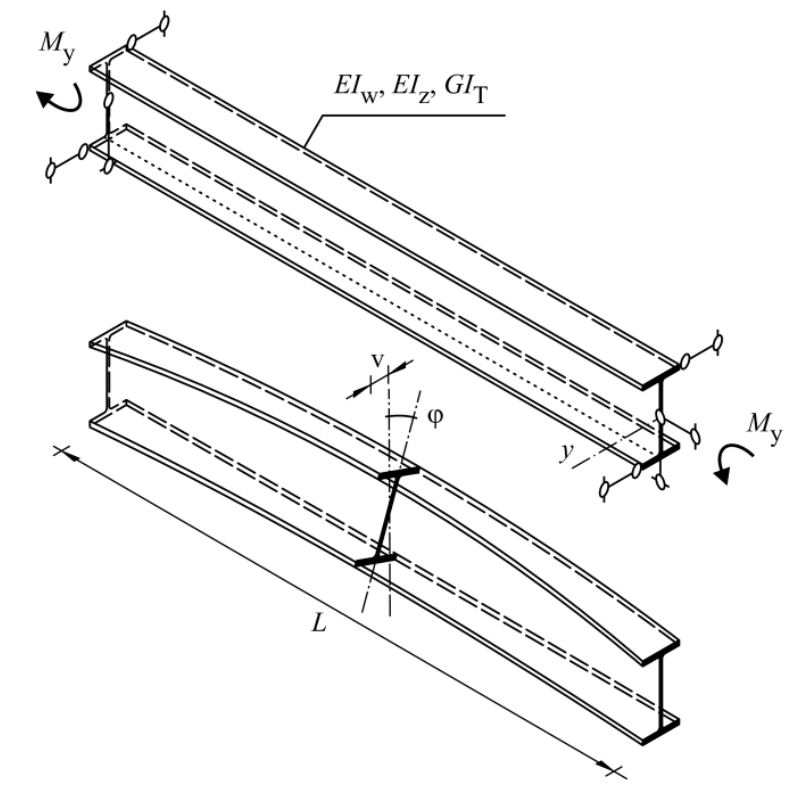

Fig.1. Beam a) supporting and loading condition, b) deformed shape. 
The formula presented in Eq.(2.1) given below is as identity with the so-called three-factor formula, employed in the ENV version of Eurocode 3 (ENV 1993-1-1:1992 Eurocode 3 [25]) reduced due to the supporting and loading conditions of a beam (where $C_{1}=1$, while $C_{2}, C_{3}$ are postponed).

$$
M_{\mathrm{cr}}=\frac{\pi^{2} E I_{\mathrm{z}}}{\left(k_{\mathrm{z}} L\right)^{2}} \sqrt{\left(\frac{k_{\mathrm{z}}}{k_{\mathrm{w}}}\right)^{2} \frac{I_{\mathrm{w}}}{I_{\mathrm{z}}}+\frac{G I_{\mathrm{T}}\left(k_{\mathrm{z}} L\right)^{2}}{\pi^{2} E I_{\mathrm{z}}}} .
$$

These support conditions are equivalent to web cleats that restraint section from deflecting laterally and twisting, while warping deformation of flanges is free (Fig.2a). The term simply supporting for example corresponds to a beam with coped ends, where the flanges are removed in the near of the joint to avoid collision with the flange of the perpendicularly located girder, or the flanges are weakened by symmetric and rounded undercutting made in order to reduce the bending moment transferred through connection. The structure of one of the described support solutions is of neglected warping fixity at endpoints, which in calculations conservatively can be assumed equal zero or close to this value, as a quasi-free restraining against warping.

The buckling moment increases and obtained differences are distinct for the end conditions, where more restraint is applied to the section, while the factor $k_{w}$ value changes to 0.5 when warping fixity is applied to the section at both ends. Such a condition of warping restraint may occur for example when flanges of I- or H- section are rigidly connected to a stiffened joint, or edges of its lower and upper flange are connected to each-other with stiff lateral plates or with ribs located on both sides of web, made of halved CHS or SHS sections (Fig.2b). For this case warping deformation at endpoints can be assumed fully restrained. For the section support where only one flange is restrained against and warping displacement and second one is free, or where ribs of small torsional stiffness are used, warping restraining of section at endpoints is flexible; therefore values of $k_{w}$ factor range between 0.5 to 1.0.



Fig.2. Details of end of beam affecting warping rigidity for a) pined b) fixed and c) spring restraints against the bi-moment. 


\section{The finite difference method for critical bending moment determination}

The fourth order differential equation for determining the critical bending moment of the lateraltorsional buckling of the beam relates one depended variable which is the angle of twist equation

$$
E I_{w} \frac{d^{4} \varphi(x)}{d x^{4}}-G I_{T} \frac{d^{2} \varphi(x)}{d x^{2}}-\frac{M_{\mathrm{y}}^{2}}{E I_{\mathrm{z}}} \varphi(x)=0
$$

where $\phi(x)$ is the angle of a twist along the span whereas $M_{y}$ is the concentrated moment applied at both end points of the beam. In order to simplify the solution the differential equation is approximated by the finite difference equation. The beam is divided for this purpose into $n$ discrete segments of constant length $\Delta x$, as it is shown in Fig.3. Internal nodes of the beam discretization are indexed $i=1,2 \ldots n$-1, whereas supporting nodes indexed with $i=0$ and $i=n$ are located at both ends of the beam, and they are fully restrained against rotation about axis $x$ - $x$ (torsion) and also translation along all axes. The additional seventh degree of freedom is to be specified as well for the thin-walled members analysis - this seventh degree of freedom is warping, whose value is equal to the rotation angle derivative resulting directly from the twisting angle equation. Two cases of warping restraints at endpoints are considered in this paper: fully restrained (support case A) and free (support case B); additionally our beam remains unrestrained laterally along its length. Two fictitious nodes located outside the beam are to be additionally inserted for the boundary conditions description in the FDM discretization - they are indexed with $i=-1$ and $i=n+1$.

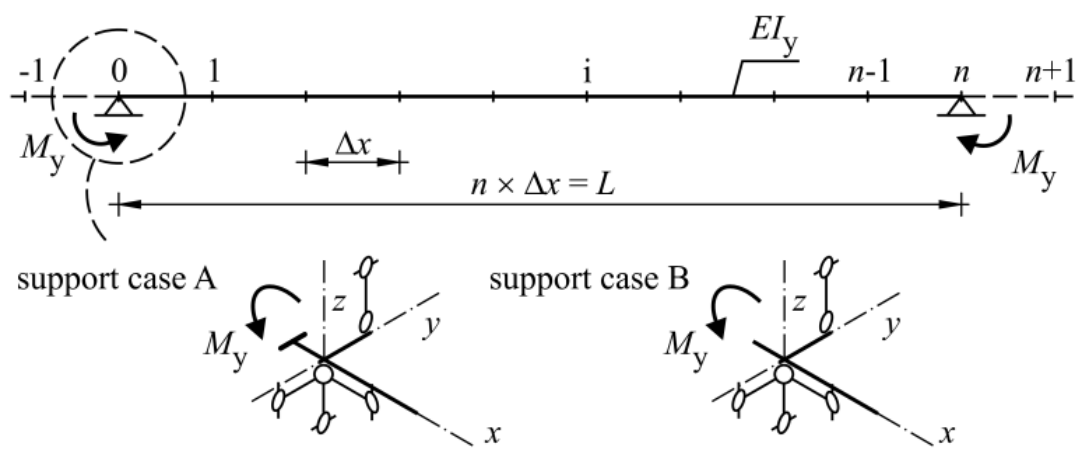

Fig.3. The static schemes available.

All the derivatives appearing in Eq.(3.1) are replaced in the FDM by the corresponding difference quotients (Liszka and Orkisz [19]; Kamiński [26]). These finite differences for the second and fourth derivatives Eqs (3.2) and (3.3) are obtained from the Taylor series truncated to first five and first seven terms, respectively. There holds

$$
\begin{aligned}
& \frac{d^{2} \varphi(x)}{d x^{2}}=\frac{\varphi_{i+1}-2 \varphi_{i}+\varphi_{i-1}}{\Delta x^{2}}, \\
& \frac{d^{4} \varphi(x)}{d x^{4}}=\frac{\varphi_{i+2}-4 \varphi_{i+1}+6 \varphi_{i}-4 \varphi_{i-1}+\varphi_{i-2}}{\Delta x^{4}} .
\end{aligned}
$$


One may transform Eq.(3.1) by using Eqs (3.2), (3.3) to the following form

$$
\begin{aligned}
& \frac{d^{4} \varphi(x)}{d x^{4}}=\frac{\varphi_{i+2}-4 \varphi_{i+1}+6 \varphi_{i}-4 \varphi_{i-1}+\varphi_{i-2}}{\Delta x^{4}} \\
& E I_{\mathrm{w}} \varphi_{i+2}-\left(4 E I_{\mathrm{w}}+G I_{\mathrm{T}} \Delta x^{2}\right) \varphi_{i+1}+\left(6 E I_{\mathrm{w}}+2 G I_{\mathrm{T}} \Delta x^{2}-\frac{M_{\mathrm{y}}^{2} \Delta x^{4}}{E I_{\mathrm{z}}}\right) \varphi_{i}+ \\
& -\left(4 E I_{\mathrm{w}}+G I_{\mathrm{T}} \Delta x^{2}\right) \varphi_{i-1}+E I_{\mathrm{w}} \varphi_{i-2}=0 .
\end{aligned}
$$

Then, a set of $n-1$ equations for internal nodes $i$ is introduced to discretize the beam into $n$ elements. Supporting and fictitious nodes are eliminated from the set of equations according to boundary conditions of the beam, where a twist is fully restrained for the supporting nodes, i.e.

$$
\varphi(0)=\varphi(L)=0 \rightarrow \varphi_{1}=\varphi_{n}=0 .
$$

The warping restraint at the end node is expressed by the relationship between values of a twist at two of its adjacent nodes. So that, its twist at both supports is fully restrained for the simply supported beam and warping is entirely free. Therefore, a twisting angle at the fictitious node is given by

$$
\varphi^{\prime \prime}(0)=\varphi^{\prime \prime}(L)=0 \rightarrow \varphi_{-1}=(-1) \varphi_{1}, \quad \varphi_{n+1}=(-1) \varphi_{n-1}
$$

Both twist and warping are restrained at the fixed support, hence

$$
\varphi^{\prime}(0)=\varphi^{\prime}(L)=0 \rightarrow \varphi_{-1}=\varphi_{1}, \quad \varphi_{n+1}=\varphi_{n-1} .
$$

The flexible restraint against warping is characterized by the stiffness $k$ as follows

$$
\varphi^{\prime}(0)=\frac{E}{k} \varphi^{\prime \prime}(0) ; \varphi^{\prime}(L)=\frac{E}{k} \varphi^{\prime \prime}(L) \rightarrow \varphi_{1}=\frac{k \Delta x+2 E}{k \Delta x-2 E} \varphi_{-1} ; \quad \varphi_{n-1}=\frac{k \Delta x+2 E}{k \Delta x-2 E} \varphi_{n+1} .
$$

We introduce matrix notation to solve Eq.(3.4) numerically - an element of Eq.(3.5) including the value of the bending moment is substituted here with the parameter $\lambda$ given by Eq.(3.10); Eq.(3.5) transforms to Eq.(3.11) due to this substitution.

$$
\begin{aligned}
& \lambda=\frac{M_{y}^{2} \Delta x^{4}}{E I_{z}}, \\
& E I_{w} \varphi_{i+2}-\left(4 E I_{w}+G I_{T} \Delta x^{2}\right) \varphi_{i+1}+\left(6 E I_{w}+2 G I_{T} \Delta x^{2}-\lambda\right) \varphi_{i}+ \\
& -\left(4 E I_{w}+G I_{T} \Delta x^{2}\right) \varphi_{i-1}+E I_{w} \varphi_{i-2}=0 .
\end{aligned}
$$


This element is located on the main diagonal of a matrix, therefore Eq.(3.11) can be expressed in the form of a homogeneous equation Eq.(3.12).

$$
(\boldsymbol{A}-\lambda \boldsymbol{I}) \Phi=0
$$

where $I$ is an identity matrix of size $n-1$. A solution of Eq.(3.1) consists of the eigenvalues of the square matrix $\boldsymbol{A}$ having the size $n-1$ and given further by Eq.(3.13). The entries of the matrix $\boldsymbol{A}$ indexed $A_{11}$ and $A_{(n-}$ 1)(n-l) differ from others located at the main diagonal of the matrix $A_{i i}$, allowing the boundary conditions Eqs (3.7) and (3.8). A coefficient $\eta$ for a simply supported beam is assumed equal to 5.0, and for a fixed support is is equal to 7.0. The eigenvalues computed correspond to the values of the elastic critical moment for consecutively modes of buckling. A relationship between the critical moment and obtained eigenvalues is given by Eq.(3.14).



$$
\begin{aligned}
& M_{c r, j}=\frac{\sqrt{\lambda_{j} E I_{z}}}{\Delta x^{2}} .
\end{aligned}
$$

Twisting angles in the internal points of division for consecutive modes of lateral-torsional buckling are equal to eigenvectors of a matrix $\boldsymbol{A}$. Of course, it is possible to obtain results for $n-1$ modes of buckling when the given beam is divided into $n$ segments. However, the finite difference method offers a different level of accuracy of numerical results for the different mode of lateral-torsional buckling. The highest accuracy is obtained for the first mode, and poor accuracy, for the last one. The decrease in accuracy for higher modes of buckling is insignificant for the structural design calculation, where in most cases, only the first mode of buckling is considered.

\section{Numerical comparison of analytical, FDM and FEM techniques}

A variety of the hot-rolled and single-bay beams (made of IPE, HEA and HEB) having the spans ranging from 4.0 to 8.0 meters long are analyzed numerically in details here; the bending moment is assumed for simplicity to be constant along their lengths. The first group of the beams is simply supported, while the other one is fixed at both supports. Computational implementation according to the FDM and analytical derivations are all programmed in the symbolic analysis program MAPLE (Char [22]). The beam is divided into $n=80$ discrete segments of the constant length equal $\Delta x=0.05 m$; internal points in these beams discretizations are indexed with $i=1,2 \ldots n-1=79$. The critical moment related to the length and warping restraints at the endpoints of the beam and obtained from the symbolic solution, by the Finite Difference Method and, concurrently, by the Finite Element Method are presented in three rows of Tabs 1 and 4 , for the simply supported and the fixed supports, correspondingly. The deformed shapes obtained from the developed FDM approach are presented in Figs 4 and 5 in the form of discrete points sets, while the adjacent continuous lines represent the corresponding analytical solution. As one may notice, all the discrete data correspond perfectly with the additional analytical results independent of the boundary 
conditions imposed at both ends. All the eigenmodes presented in Figs 4 and 5 clearly reflect the boundary conditions applied in both case studies, even in the FDM numerical solutions. The critical moment obtained from the developed FDM approach and determined for the beams having different lengths and various cross-sections, the exact solution described e.g., in the Eurocode rules, and the corresponding FEM approach are compared all in Tabs 1-6.



Fig.4. The first five eigenmodes for the simply supported beam.

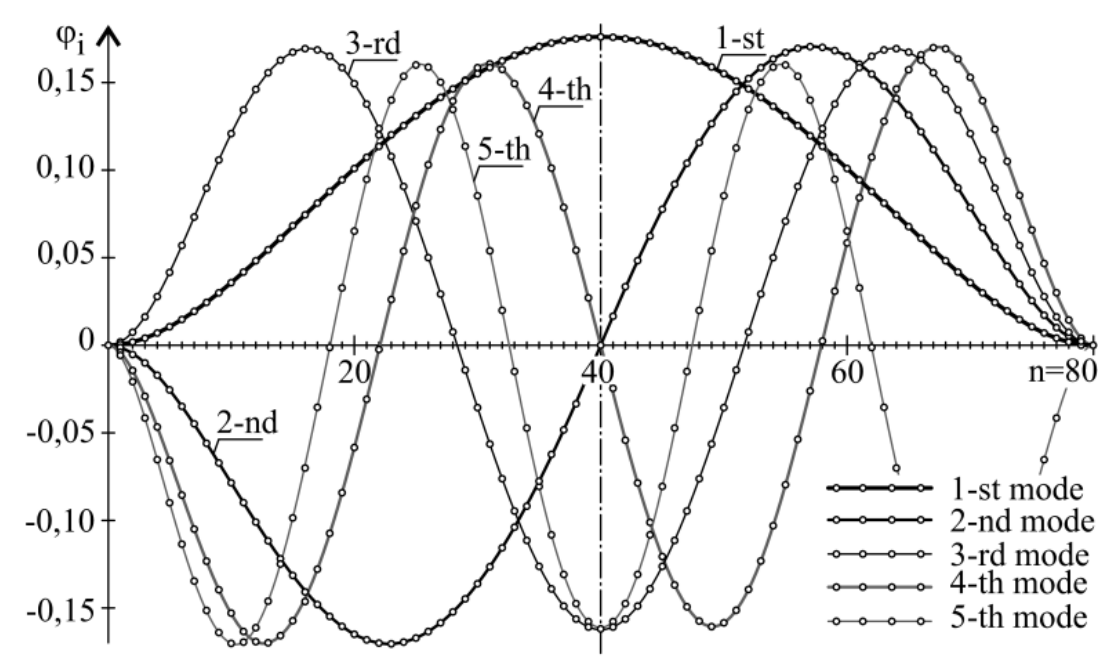

Fig.5. The first five eigenmodes for the beam fixed at both ends. 
Table 1. Elastic critical moment for the simply supported beam with the HEB cross-section.

\begin{tabular}{|c|c|c|c|c|c|c|c|c|c|c|c|}
\hline \multirow{2}{*}{$\begin{array}{l}\text { Section } \\
\text { HEB }\end{array}$} & \multirow{2}{*}{ Method } & \multicolumn{10}{|c|}{ Length $[\mathrm{m}]$} \\
\hline & & 4.0 & 4.5 & 5.0 & 5.5 & 6.0 & 6.5 & 7.0 & 7.5 & 8.0 & 8.5 \\
\hline \multirow{3}{*}{160} & FDM & 190.87 & 166.13 & 147.20 & 132.24 & 120.11 & 110.07 & 101.61 & 94.38 & 88.14 & 82.68 \\
\hline & explicit & 190.91 & 166.17 & 147.24 & 132.27 & 120.14 & 110.09 & 101.63 & 94.40 & 88.15 & 82.70 \\
\hline & FEM & 190.78 & 166.05 & 147.12 & 132.16 & 120.03 & 109.99 & 101.53 & 94.31 & 88.07 & 82.61 \\
\hline \multirow{3}{*}{180} & FDM & 285.89 & 247.05 & 217.68 & 194.69 & 176.20 & 161.00 & 148.28 & 137.47 & 128.16 & 120.06 \\
\hline & explicit & 285.96 & 247.11 & 217.73 & 194.73 & 176.24 & 161.04 & 148.31 & 137.50 & 128.19 & 120.08 \\
\hline & FEM & 286.47 & 247.54 & 218.11 & 195.08 & 176.56 & 161.33 & 148.57 & 137.74 & 128.42 & 120.30 \\
\hline \multirow{3}{*}{200} & FDM & 426.87 & 366.69 & 321.56 & 286.51 & 258.50 & 235.60 & 216.53 & 200.38 & 186.54 & 174.53 \\
\hline & explicit & 426.98 & 366.78 & 321.64 & 286.57 & 258.55 & 235.65 & 216.57 & 200.43 & 186.58 & 174.57 \\
\hline & FEM & 427.46 & 367.19 & 321.96 & 286.87 & 258.82 & 235.89 & 216.78 & 200.62 & 186.75 & 174.73 \\
\hline \multirow{3}{*}{220} & FDM & 607.76 & 518.21 & 451.68 & 400.44 & 359.81 & 326.82 & 299.51 & 276.51 & 256.89 & 239.93 \\
\hline & explicit & 607.93 & 518.35 & 451.80 & 400.54 & 359.90 & 326.90 & 299.58 & 276.58 & 256.94 & 239.98 \\
\hline & FEM & 608.98 & 519.26 & 452.58 & 401.25 & 360.53 & 327.48 & 300.11 & 277.07 & 257.40 & 240.40 \\
\hline \multirow{3}{*}{240} & FDM & 862.47 & 731.18 & 634.26 & 560.04 & 501.52 & 454.25 & 415.29 & 382.62 & 354.85 & 330.93 \\
\hline & explicit & 862.71 & 731.38 & 634.42 & 560.18 & 501.65 & 454.36 & 415.38 & 382.71 & 354.92 & 331.00 \\
\hline & FEM & 863.53 & 732.06 & 635.01 & 560.73 & 502.14 & 454.80 & 415.80 & 383.09 & 355.29 & 331.33 \\
\hline \multirow{3}{*}{260} & FDM & 1147.29 & 965.61 & 832.41 & 731.11 & 651.76 & 588.04 & 535.82 & 492.27 & 455.41 & 423.81 \\
\hline & explicit & 1147.62 & 965.88 & 832.63 & 731.30 & 651.92 & 588.19 & 535.95 & 492.39 & 455.52 & 423.91 \\
\hline & FEM & 1149.00 & 967.10 & 833.74 & 732.30 & 652.83 & 589.02 & 536.74 & 493.13 & 456.21 & 424.56 \\
\hline \multirow{3}{*}{280} & FDM & 1498.28 & 1251.61 & 1071.85 & 935.99 & 830.21 & 745.78 & 676.97 & 619.89 & 571.82 & 530.79 \\
\hline & explicit & 1498.73 & 1251.98 & 1072.15 & 936.25 & 830.43 & 745.97 & 677.14 & 620.04 & 571.95 & 530.92 \\
\hline & FEM & 1499.90 & 1253.00 & 1073.00 & 936.95 & 831.05 & 746.52 & 677.67 & 620.48 & 572.39 & 531.34 \\
\hline \multirow{3}{*}{300} & FDM & 2024.17 & 1683.71 & 1436.35 & 1249.98 & 1105.34 & 990.26 & 896.77 & 819.44 & 754.50 & 699.23 \\
\hline & explicit & 2024.79 & 1684.21 & 1436.76 & 1250.33 & 1105.64 & 990.52 & 897.00 & 819.65 & 754.69 & 699.40 \\
\hline & FEM & 2023.30 & 1682.70 & 1435.40 & 1249.10 & 1104.40 & 989.38 & 895.87 & 818.60 & 753.66 & 698.43 \\
\hline \multirow{3}{*}{320} & FDM & 2323.69 & 1932.41 & 1648.16 & 1434.04 & 1267.88 & 1135.71 & 1028.34 & 939.56 & 865.02 & 801.58 \\
\hline & explicit & 2324.41 & 1932.98 & 1648.63 & 1434.44 & 1268.22 & 1136.01 & 1028.61 & 939.80 & 865.23 & 801.77 \\
\hline & FEM & 2325.90 & 1934.40 & 1649.90 & 1435.70 & 1269.40 & 1137.10 & 1029.70 & 940.80 & 866.15 & 802.67 \\
\hline \multirow{3}{*}{340} & FDM & 2570.12 & 2135.12 & 1819.32 & 1581.61 & 1397.29 & 1250.77 & 1131.85 & 1033.58 & 951.12 & 881.00 \\
\hline & explicit & 2570.92 & 2135.76 & 1819.85 & 1582.05 & 1397.67 & 1251.10 & 1132.14 & 1033.84 & 951.35 & 881.21 \\
\hline & FEM & 2575.70 & 2139.90 & 1823.60 & 1585.40 & 1400.80 & 1253.90 & 1134.70 & 1036.30 & 953.61 & 883.36 \\
\hline
\end{tabular}


Table 2. Elastic critical moment for the simply supported beam with the IPE cross-section.

\begin{tabular}{|c|c|c|c|c|c|c|c|c|c|c|c|}
\hline \multirow{2}{*}{$\begin{array}{l}\text { Section } \\
\text { IPE }\end{array}$} & \multirow{2}{*}{ Method } & \multicolumn{10}{|c|}{ Length $[\mathrm{m}]$} \\
\hline & & 4.0 & 4.5 & 5.0 & 5.5 & 6.0 & 6.5 & 7.0 & 7.5 & 8.0 & 8.5 \\
\hline \multirow{3}{*}{200} & FDM & 36.73 & 31.85 & 28.15 & 25.23 & 22.87 & 20.93 & 19.30 & 17.91 & 16.71 & 15.67 \\
\hline & explicit & 36.74 & 31.86 & 28.15 & 25.23 & 22.88 & 20.94 & 19.30 & 17.91 & 16.72 & 15.67 \\
\hline & FEM & 36.56 & 31.69 & 27.99 & 25.09 & 22.74 & 20.80 & 19.18 & 17.80 & 16.60 & 15.56 \\
\hline \multirow{3}{*}{220} & FDM & 52.23 & 45.01 & 39.58 & 35.34 & 31.94 & 29.15 & 26.82 & 24.85 & 23.15 & 21.67 \\
\hline & explicit & 52.25 & 45.03 & 39.59 & 35.35 & 31.94 & 29.16 & 26.83 & 24.85 & 23.15 & 21.68 \\
\hline & FEM & 52.14 & 44.92 & 39.49 & 35.25 & 31.86 & 29.07 & 26.75 & 24.78 & 23.08 & 21.61 \\
\hline \multirow{3}{*}{240} & FDM & 75.79 & 65.14 & 57.15 & 50.94 & 45.97 & 41.91 & 38.52 & 35.66 & 33.20 & 31.06 \\
\hline & explicit & 75.81 & 65.16 & 57.16 & 50.95 & 45.98 & 41.92 & 38.53 & 35.66 & 33.20 & 31.07 \\
\hline & FEM & 74.54 & 63.98 & 56.08 & 49.94 & 04 & 41.03 & 37.70 & 34.88 & 2.47 & 30.37 \\
\hline \multirow{3}{*}{270} & FDM & 110.45 & 93.88 & 81.62 & 72.20 & 64.76 & 4 & 76 & 9.58 & 6.02 & 42.94 \\
\hline & explicit & 110.48 & 93.91 & 81.64 & 72.22 & 64.78 & 58.75 & 53.77 & 49.59 & 46.03 & 42.95 \\
\hline & FEM & 109.09 & 92.60 & 80.41 & 71.07 & 63.69 & 57.73 & 52.81 & 48.68 & 45.16 & 42.13 \\
\hline \multirow{3}{*}{300} & FDM & 160.85 & 135.38 & 116.71 & 102.50 & 91.38 & 82.44 & 75.12 & 69.02 & 63.85 & 59.42 \\
\hline & explicit & 160.90 & 135.42 & 116.74 & 102.53 & 91.40 & 82.46 & 75.14 & 69.03 & 63.86 & 59.43 \\
\hline & FEM & 159.21 & 133.82 & 115.22 & 101.09 & 90.04 & 81.17 & 73.91 & 67.87 & 2.75 & 58.37 \\
\hline \multirow{3}{*}{330} & FDM & 223.90 & 187.73 & 161.30 & 141.27 & 125.62 & 113.10 & 102.86 & 94.35 & 87.16 & 81.01 \\
\hline & explicit & 223.96 & 187.79 & 161.35 & 141.31 & 125.65 & 113.13 & 102.89 & 94.37 & 87.18 & 81.03 \\
\hline & FEM & 221.76 & 185.65 & 159.32 & 139.37 & 123.81 & 111.37 & 101.21 & 92.77 & 85.66 & 79.58 \\
\hline \multirow{3}{*}{360} & FDM & 310.65 & 259.18 & 221.71 & 193.42 & 171.41 & 153.86 & 139.57 & 127.72 & 117.76 & 109.26 \\
\hline & explicit & 310.74 & 259.26 & 221.77 & 193.47 & 171.45 & 153.90 & 139.60 & 127.76 & 117.79 & 109.28 \\
\hline & FEM & 309.17 & 257.66 & 220.18 & 191.91 & 169.94 & 152.43 & 138.19 & 126.40 & 116.47 & 108.02 \\
\hline \multirow{3}{*}{400} & FDM & 425.53 & 353.66 & 301.47 & 262.18 & 231.70 & 207.47 & 187.79 & 171.52 & 157.87 & 146.26 \\
\hline & explicit & 425.66 & 353.77 & 301.56 & 262.25 & 231.76 & 207.52 & 187.84 & 171.57 & 157.91 & 146.29 \\
\hline & FEM & 422.06 & 35 & 22 & 2 & 2 & 20 & 18 & 87 & 155.33 & 143.82 \\
\hline \multirow{3}{*}{450} & FDM & 586.83 & 484.90 & 411.14 & 355.81 & 313.06 & 279.21 & 251.84 & 229.30 & 210.46 & 194.49 \\
\hline & explicit & 587.02 & 485.05 & 411.26 & 355.91 & 313.15 & 279.29 & 251.91 & 229.36 & 210.51 & 194.54 \\
\hline & FEM & 582.58 & 480.74 & 407.10 & 351.93 & 309.33 & 275.63 & 248.40 & 226.00 & 207.29 & 191.44 \\
\hline \multirow{3}{*}{500} & FDM & 809.15 & 665.55 & 561.88 & 484.33 & 424.59 & 377.41 & 339.38 & 308.17 & 282.15 & 260.16 \\
\hline & explicit & 809.42 & 665.76 & 562.06 & 484.48 & 424.71 & 377.52 & 339.48 & 308.25 & 282.22 & 260.22 \\
\hline & FEM & 806.34 & 662.54 & 558.81 & 481.23 & 421.51 & 374.39 & 336.43 & 305.27 & 279.34 & 257.43 \\
\hline
\end{tabular}


Table 3. Elastic critical moment for the simply supported beam with the HEA cross-section.

\begin{tabular}{|c|c|c|c|c|c|c|c|c|c|c|c|}
\hline \multirow{2}{*}{$\begin{array}{l}\text { Section } \\
\text { HEA }\end{array}$} & \multirow{2}{*}{ Method } & \multicolumn{10}{|c|}{ Length $[\mathrm{m}]$} \\
\hline & & 4.0 & 4.5 & 5.0 & 5.5 & 6.0 & 6.5 & 7.0 & 7.5 & 8.0 & 8.5 \\
\hline \multirow{3}{*}{140} & FDM & 65.52 & 56.82 & 50.21 & 45.01 & 40.81 & 37.34 & 34.43 & 31.95 & 29.81 & 27.95 \\
\hline & explici & 65.53 & 56.83 & 50.22 & 45.02 & 40.82 & 37.35 & 34.44 & 31.96 & 29.82 & 27.95 \\
\hline & FEM & 65.33 & 56.65 & 50.05 & 44.86 & 40.67 & 37.21 & 34.31 & 31.84 & 29.70 & 27.85 \\
\hline \multirow{3}{*}{160} & FDM & 105.29 & 90.67 & 79.68 & 71.11 & 64.24 & 58.62 & 53.92 & 49.94 & 46.52 & 43.55 \\
\hline & explicit & 105.31 & 90.70 & 79.69 & 71.12 & 64.26 & 58.63 & 53.93 & 49.95 & 46.53 & 43.56 \\
\hline & FEM & 104.26 & 89.72 & 78.78 & 70.28 & 63.46 & 57.89 & 53.24 & 49.30 & 45.91 & 42.97 \\
\hline \multirow{3}{*}{180} & FDM & 153.79 & 130.92 & 113.96 & 100.92 & 90.59 & 82.22 & 75.30 & 69.48 & 64.52 & 60.24 \\
\hline & explici & 153.83 & 130.95 & 113.99 & 100.94 & 90.61 & 82.24 & 75.32 & 69.50 & 64.53 & 60.25 \\
\hline & FEM & 153.21 & 130.38 & 113.44 & 100.43 & 90.14 & 81.79 & 74.89 & 69.09 & 64.15 & 59.89 \\
\hline \multirow{3}{*}{200} & FDM & 231.33 & 195.64 & 169.34 & 149.26 & 133.46 & 120.73 & 110.25 & 101.49 & 94.04 & 87.64 \\
\hline & explic & 231.40 & 195.69 & 169.39 & 149.30 & 133.50 & 120.76 & 110.28 & 101.51 & 94.06 & 87.66 \\
\hline & FEM & 229.29 & 193.71 & 167.53 & 147.54 & 131.84 & 119.19 & 108.80 & 100.11 & 92.73 & 86.40 \\
\hline \multirow{3}{*}{220} & FDM & 348.64 & 292.47 & 251.40 & 220.25 & 195.92 & 176.44 & 160.51 & 147.26 & 136.06 & 126.49 \\
\hline & explicit & 348.74 & 292.55 & 251.47 & 220.31 & 195.97 & 176.48 & 160.55 & 147.29 & 136.10 & 126.52 \\
\hline & FEM & 347.32 & 291.20 & 250.17 & 219.09 & 194.79 & 175.37 & 159.48 & 146.28 & 135.13 & 125.60 \\
\hline \multirow{3}{*}{240} & FDM & 522.45 & 436.32 & 373.57 & 326.15 & 289.24 & 259.78 & 235.78 & 215.87 & 199.11 & 184.81 \\
\hline & explic & 522.61 & 436.45 & 373.68 & 326.24 & 289.32 & 259.85 & 235.84 & 215.93 & 199.16 & 184.85 \\
\hline & FEM & 520.14 & 434.08 & 371.40 & 324.07 & 287.25 & 257.87 & 233.96 & 214.13 & \begin{tabular}{|l}
197.43 \\
\end{tabular} & 183.21 \\
\hline \multirow{3}{*}{260} & FDM & 720.29 & 597.71 & 508.79 & 441.90 & 390.08 & 348.92 & 315.54 & 287.98 & 264.86 & 245.22 \\
\hline & explicit & 720.52 & 597.89 & 508.94 & 442.03 & 390.19 & 349.01 & 315.62 & 288.05 & 264.93 & 245.28 \\
\hline & FEM & 716.92 & 594.42 & 505.58 & 438.81 & 387.12 & 346.07 & 312.81 & 285.35 & 262.34 & 242.80 \\
\hline \multirow{3}{*}{280} & FDM & 968.07 & 797.77 & 674.71 & 582.55 & 511.48 & 455.29 & 409.94 & 372.66 & 341.55 & 315.23 \\
\hline & explici & 968.38 & 798.02 & 674.92 & 582.73 & 511.62 & 455.42 & 410.05 & 372.76 & 341.64 & 315.31 \\
\hline & FEM & 964.42 & 794.19 & 671.20 & 579.13 & 508.15 & 452.09 & 406.83 & 369.69 & 338.68 & 312.47 \\
\hline \multirow{3}{*}{300} & FDM & 1353.52 & 1112.24 & 938.14 & 807.97 & 707.74 & 628.65 & 564.93 & 512.66 & 469.11 & 432.34 \\
\hline & explic & 1353.97 & 1112.60 & 938.43 & 808.21 & 707.95 & 628.83 & 565.08 & 512.80 & 469.23 & 432.45 \\
\hline & FEM & 1348.40 & 1107.10 & 933.04 & 802.98 & 702.88 & 623.90 & 560.33 & 508.21 & 464.81 & 428.19 \\
\hline \multirow{3}{*}{320} & FDM & 1600.61 & 1315.47 & 1109.70 & 955.84 & 837.36 & 743.87 & 668.53 & 606.73 & 555.23 & 511.74 \\
\hline & explicit & 1601.14 & 1315.88 & 1110.04 & 956.12 & 837.61 & 744.08 & 668.71 & 606.89 & 555.38 & 511.88 \\
\hline & FEM & 1599.00 & 1313.70 & 11107.90 & 953.98 & 835.51 & 742.00 & 666.75 & 604.98 & 553.53 & 510.07 \\
\hline
\end{tabular}

The results contained in Tab.1 for the HEB profiles document very well that the analytical solution agrees very well with the critical moment values returned by both FDM and FEM computational approaches. Even the results obtained for a combination of the largest length of the beam and the largest steel profile give the difference in-between all of these methods in the range of a single promile or two. Nevertheless, the FDM technique is apparently closer to the analytics than the FEM. This table confirms naturally that the larger the element length, the smaller its critical moment. A quite inverse relation is noticed in case of the cross-section variations, where increasing of its height increases the overall critical moment value. The given variability ranges of both design parameters result in a larger sensitivity of this critical moment with respect to the cross section type. Then it is clear that we need to apply a larger profile to shorten the length of a beam when the critical moment is smaller than its admissible counterpart. The coincidence in-between these methods is also very convenient for the designers because the analytical method is accurate and available for rather simple 
beams with limited types of loadings and applications in practical solutions, while the FDM is applicable for the regular geometries rather and preferred with the constant cross-sections. The FEM is recommended especially for complex boundary conditions (e.g., with anti-twist elastic protection) as well as the plate girders with the varying web height. Tables 2 and 3 show that this almost perfect coincidence of all the numerical techniques applied now is observed also for the HEA and IPE profiles. Of course, the critical moment for the beam of the same length and the same web height (e.g., 300) made of various profiles is always the largest in case of the HEB profile, significantly smaller for the HEA profile and the smallest for the IPE shape. However, a designing procedure for the pure bending does not exhibit such tremendous differences like the critical moment analysis, where $\mathrm{M}_{\mathrm{cr}}(\mathrm{HEB} 300)=2024 \mathrm{kNm}>\mathrm{M}_{\mathrm{cr}}(\mathrm{HEA300})=1354 \mathrm{kNm}>>\mathrm{M}_{\mathrm{cr}}($ IPE300 $)=160 \mathrm{kNm}$ at the minimum length of the beam. Furthermore, we observe very similar fluctuations of the critical moment resulting from the additional variations of both input parameters $-\mathrm{M}_{\mathrm{cr}}$ dominantly increases together with an increase of the profile size and also decreases while increasing the beam length. The majority of the HEB profiles is even more transparent when comparing Figs 6-8 - absolute extreme values are obtained for this profile in case of any size and any length of the beam analyzed. The designers are able to replace the HEB profiles by the additionally larger HEA cross-sections, while a replacement with the IPE profiles is not advisable since significant mass increases after a mandatory increase of the web height. A comparison of the FEM results contained in Tabs 1-3 enables an interesting observation that the critical moment obtained by this method underestimates a little bit its analytical value for the HEA and IPE profiles. A situation with the HEB profiles is more complex as some small underestimation is noticed for the smallest profile, while an overestimation appears for the entire rest of the HEB cross-sections family. The results concerning the beam fixed at both ends contained in Tabs 4-6 as well as in Figs 9-11 exhibit very apparent and systematic difference and underestimation of the analytical method in relation to both FDM and FEM. This difference may be even larger than $10 \%$ for the extremely large steel profiles and the beams of practically any length included in this study. It is a very satisfactory conclusion for practitioners in civil engineering who design steel elements and prevent them against torsional-bending buckling using analytical formulas because they have apparently larger safety margins in this case. All the remaining facts dealing with the parameter variability of $\mathrm{M}_{\mathrm{cr}}$ with respect to the profile size and the beam length as well as the dominating role of the HEBs noticed for the simply supported beams remain the same for the clamped-clamped structure. Right now a domination of the HEB profile over the IPE one is equivalent to almost ten times of the critical moment capacity of the given beam.

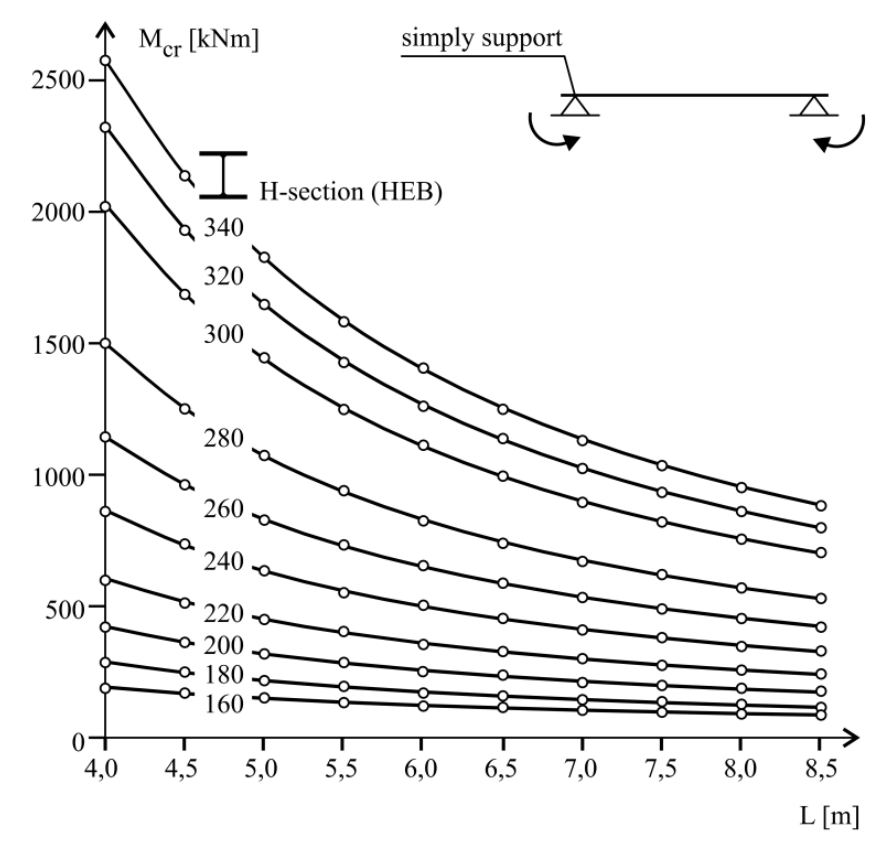

Fig.6. Critical moment versus beam length by the FDM for simply supported beams with the HEB crosssection. 


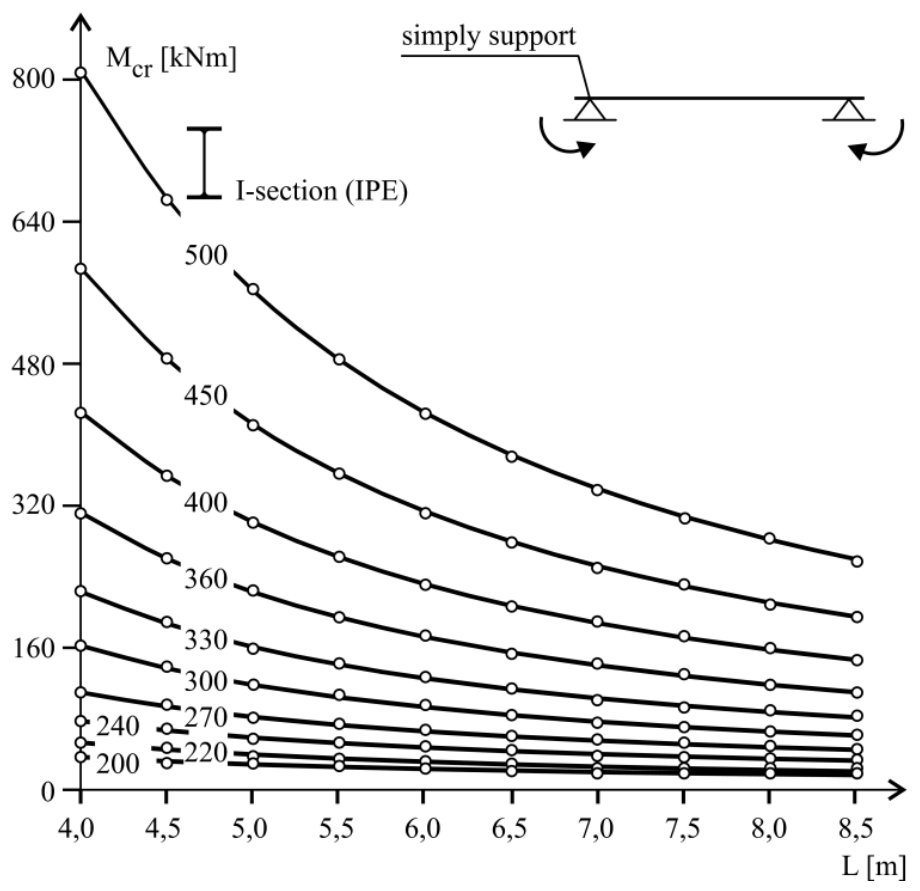

Fig.7. Critical moment versus beam length by the FDM for simply supported beams with the IPE crosssection.

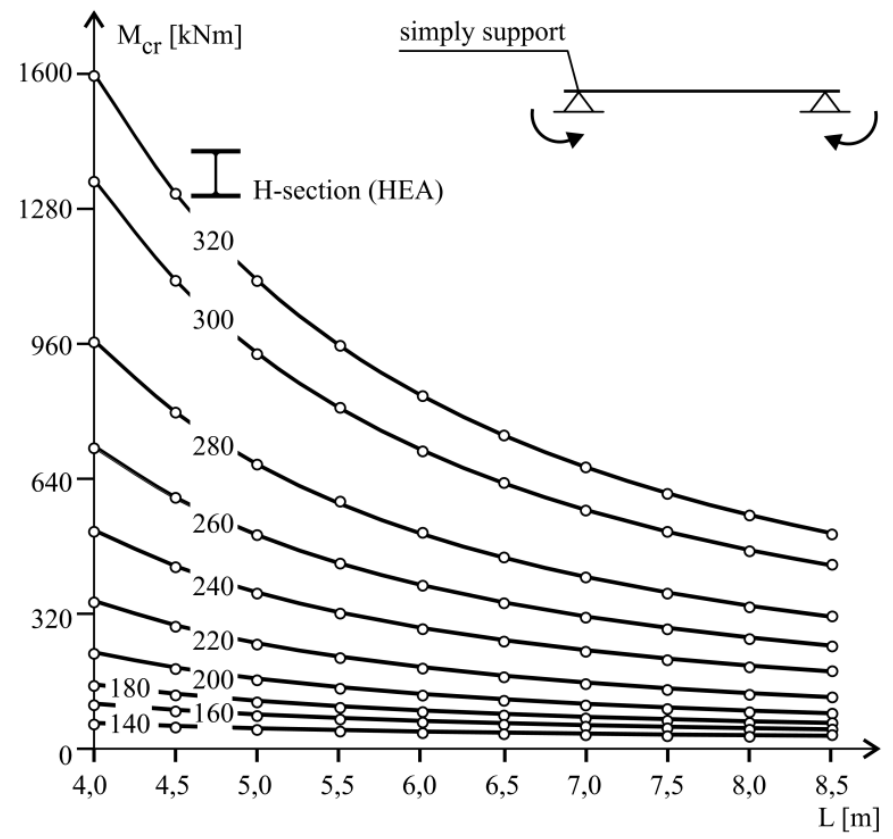

Fig.8. Critical moment versus beam length by the FDM for simply supported beams with the HEA crosssection. 
Table 4. Elastic critical moment for the clamped-clamped beam with the HEB cross-section.

\begin{tabular}{|c|c|c|c|c|c|c|c|c|c|c|c|}
\hline \multirow{2}{*}{\begin{tabular}{|l|} 
Section \\
HEB \\
\end{tabular}} & \multirow{2}{*}{ Method } & \multicolumn{10}{|c|}{ Length $[m]$} \\
\hline & & 4.0 & 4.5 & 5.0 & 5.5 & 6.0 & 6.5 & 7.0 & 7.5 & 8.0 & 8.5 \\
\hline \multirow{3}{*}{160} & FDM & 269.05 & 225.81 & 194.09 & 169.98 & 151.09 & 135.92 & 123.50 & 113.15 & 104.40 & 96.90 \\
\hline & explic & 240.61 & 202.49 & 174.54 & 153.29 & 136.64 & 123.27 & 112.32 & 103.19 & 95.45 & 88.83 \\
\hline & FEM & 269.30 & 225.98 & 194.23 & 170.07 & 151.16 & 135.99 & 123.55 & 113.19 & 104.43 & 96.94 \\
\hline \multirow{3}{*}{180} & FDM & 428.69 & 356.10 & 303.31 & 263.51 & 232.60 & 207.99 & 187.98 & 171.43 & 57.53 & 145.70 \\
\hline & explici & 382.04 & 318.01 & 1.47 & 236.38 & 09.14 & 187.45 & 99.82 & 155.24 & 42.98 & 132.54 \\
\hline & FEM & 429.81 & 35 & 304.09 & 264.19 & 233 & 2 & 188 & 1 & 4 & 46.09 \\
\hline \multirow{3}{*}{200} & FDM & 669.45 & 2.19 & 467.32 & 403.65 & 54.44 & 315.47 & 283.94 & 257.99 & 36.29 & 217.91 \\
\hline & explicit & 595.46 & 492.00 & 417.14 & 360.99 & 317.61 & 283.26 & 255.48 & 232.61 & 213.49 & 197.29 \\
\hline & FEM & 670.96 & 553.44 & 468.35 & 404.51 & 355.19 & 316.10 & 284.53 & 258.51 & 236.77 & 218.34 \\
\hline \multirow{3}{*}{220} & FDM & & 8 & 689.50 & 591.73 & 516.52 & 4 & 409.54 & 6 & 94 & 310.52 \\
\hline & explici & 8 & 729.47 & 613.97 & 1 & לנ.J. & 409.12 & 367.07 & 332.62 & 303.96 & 279.80 \\
\hline & FEM & 1004.50 & 822.45 & 91.22 & 593.23 & 517.82 & 458.40 & 410.58 & 371.40 & 338.81 & 311.31 \\
\hline \multirow{3}{*}{240} & FDM & .28 & 1199.70 & 1003.59 & 857 & 75.33 & 657.23 & 586.53 & 28.80 & 80.91 & 440.66 \\
\hline & explicit & 1306.06 & 1065.45 & 92.37 & 763.41 & 664.51 & 586.80 & 524.47 & 473.56 & 431.35 & 395.87 \\
\hline & FEM & ) & 120 & 20 & 8 & 746.58 & 33 & 5 & 529.72 & .75 & 441.44 \\
\hline \multirow{3}{*}{260} & FDM & 15 & 1652.70 & 5.34 & 1169.10 & .31 & 61 & 8.72 & 708.19 & 1.61 & 585.83 \\
\hline & explic & 1806.99 & 1466.01 & 21.17 & 1039.15 & 899.91 & 790.80 & 703.54 & 632.51 & 573.81 & 524.63 \\
\hline & FEM & 2042.50 & 1655.60 & 1377.90 & 1171.30 & 1013.20 & 889.34 & 790.22 & 709.59 & 642.88 & 587.04 \\
\hline \multirow{3}{*}{280} & FDM & 2765.35 & 2231.05 & 1847.88 & 1563.44 & 1346.23 & 1176.36 & 1040.81 & 930.74 & 840.00 & 764.19 \\
\hline & explic & 2448.85 & 1977.11 & 1638.84 & 1387.75 & 1196.03 & 1046.12 & 926.51 & 829.40 & 749.36 & 682.50 \\
\hline & FEM & 27 & 0 & $\overline{0}$ & 90 & & 1178.30 & 1042.50 & 932.25 & 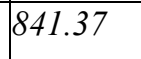 & 765.38 \\
\hline \multirow{3}{*}{300} & FDM & 5 & 7 & 7 & 52 & 7 & 03 & 12 & .73 & .25 & 1031.57 \\
\hline & explicit & 3374.32 & 2717.60 & 2246.94 & 1897.83 & 1631.47 & 1423.40 & 1257.57 & 1123.10 & 1012.40 & 920.05 \\
\hline & FEM & 3814.10 & 3069.50 & 2536.20 & 2140.40 & 1838.40 & 1602.50 & 1414.40 & 1261.90 & 1136.40 & 1031.60 \\
\hline \multirow{3}{*}{320} & FDM & 7 & 3525.38 & 5 & 2457.79 & 211 & 1839.88 & 1623.87 & 1448.69 & 1304.47 & 1184.15 \\
\hline & explic & 3 & 50 & 15 & 97 & 5 & 55 & 02 & 44 & 20 & 07 \\
\hline & FEM & 4385.70 & 3529.40 & 916.00 & 2460.90 & 211 & 1842.30 & 1626.10 & 1450.70 & 1306.40 & 1185.90 \\
\hline \multirow{3}{*}{340} & FDM & 4868.16 & 3915.63 & 3233.03 & 2726.76 & 2340.55 & 2038.89 & 1798.51 & 1603.62 & 1443.22 & 1309.45 \\
\hline & explicit & 4308.94 & 3467.91 & 2865.23 & 2418.29 & 2077.36 & 1811.10 & 1598.96 & 1426.98 & 1285.46 & 1167.45 \\
\hline & FEM & & 0 & 40.70 & 2733.50 & 2346.60 & 2044.10 & 180 & 16 & 1447.10 & 13 \\
\hline
\end{tabular}


Table 5. Elastic critical moment for the clamped-clamped beam with the IPE cross-section.

\begin{tabular}{|c|c|c|c|c|c|c|c|c|c|c|c|}
\hline \multirow{2}{*}{\begin{tabular}{|l} 
Section \\
IPE \\
\end{tabular}} & \multirow{2}{*}{ Method } & \multicolumn{10}{|c|}{ Length $[\mathrm{m}]$} \\
\hline & & 4.0 & 4.5 & 5.0 & 5.5 & 6.0 & 6.5 & 7.0 & 7.5 & 8.0 & 8.5 \\
\hline \multirow{3}{*}{200} & FDM & 53.48 & 44.64 & 38.18 & 33.30 & 29.49 & 26.45 & 23.97 & 21.91 & 20.17 & 18.69 \\
\hline & explicit & 47.73 & 39.93 & 34.25 & 29.94 & 26.59 & 23.91 & 21.72 & 19.90 & 18.37 & 17.06 \\
\hline & FEM & 53.46 & 44.59 & 38.13 & 33.23 & 29.42 & 26.38 & 23.89 & 21.83 & 20.10 & 18.62 \\
\hline \multirow{3}{*}{220} & FDM & 79.98 & 66.21 & 56.23 & 48.72 & 42.90 & 38.28 & 34.53 & 31.44 & 28.84 & 26.64 \\
\hline & explicit & 71.21 & 59.06 & 50.26 & 43.64 & 38.51 & 34.44 & 31.13 & 28.41 & 26.12 & 24.18 \\
\hline & FEM & 80.01 & 66.22 & 56.22 & 48.70 & 42.88 & 38.25 & 34.50 & 31.41 & 28.81 & 26.61 \\
\hline \multirow{3}{*}{240} & FDM & 118.41 & 97.72 & 82.75 & 71.51 & 62.82 & 55.93 & 50.36 & 45.78 & 41.94 & 38.69 \\
\hline & explicit & 105.33 & 87.09 & 73.88 & 63.97 & 56.31 & 50.24 & 45.33 & 41.29 & 37.90 & 35.04 \\
\hline & FEM & 117.61 & 96.93 & 81.97 & 70.75 & 62.09 & 55.23 & 49.68 & 45.12 & 41.31 & 38.08 \\
\hline \multirow{3}{*}{270} & FDM & 185.62 & 151.58 & 127.06 & 108.78 & 94.73 & 83.68 & 74.80 & 67.54 & 61.51 & 56.44 \\
\hline & explicit & 164.73 & 134.68 & 113.05 & 96.92 & 84.53 & 1.78 & 66.96 & 60.56 & 55.24 & 50.77 \\
\hline & FEM & 184.92 & 150.84 & 126.30 & 108.02 & 93.98 & 82.94 & 74.08 & 66.83 & 0.83 & 55.77 \\
\hline \multirow{5}{*}{300} & FDM & 285.88 & 231.72 & 192.83 & 163.92 & 141.79 & 124.45 & 110.58 & 99.29 & 89.96 & 82.14 \\
\hline & explicit & 253.36 & 205.55 & 171.22 & 145.70 & 126.17 & 110.87 & 98.64 & 88.68 & 80.45 & 73.56 \\
\hline & FEM & 285.19 & 230.94 & 192.00 & 163.06 & 140.93 & 123.60 & 109.73 & 98.45 & 89.13 & 81.33 \\
\hline & explicit & 359.42 & 290.85 & 241.66 & 205.12 & 177.20 & 155.34 & 137.88 & 123.69 & 111.98 & 102.19 \\
\hline & FEM & 405.00 & 327.18 & 271.36 & 229.90 & 198.23 & 173.45 & 153.66 & 137.57 & 124.30 & 113.20 \\
\hline \multirow{3}{*}{360} & FDM & 576.79 & 465.01 & 384.87 & 325.39 & 279.98 & 244.48 & 216.16 & 193.17 & 174.23 & 158.41 \\
\hline & explicit & 510.71 & 412.03 & 341.27 & 288.77 & 248.68 & 217.35 & 192.36 & 172.08 & 155.37 & 141.42 \\
\hline & FEM & 577.36 & 465.18 & 384.77 & 325.10 & 279.56 & 243.94 & 215.56 & 192.52 & 173.54 & 157.70 \\
\hline \multirow{3}{*}{400} & FDM & 804.39 & 647.15 & 534.46 & 450.88 & 387.11 & 337.30 & 297.60 & 265.42 & 238.92 & 216.82 \\
\hline & explicit & 712.01 & 573.17 & 473.68 & 399.89 & 343.60 & 299.64 & 264.61 & 236.20 & 212.83 & 193.33 \\
\hline & FEM & 803.28 & 645.81 & 532.96 & 449.25 & 385.41 & 335.57 & 295.85 & 263.67 & 237.18 & 215.09 \\
\hline \multirow{3}{*}{450} & FDM & 1138.06 & 912.95 & 751.71 & 632.21 & 541.11 & 470.03 & 413.45 & 367.64 & 329.98 & 298.62 \\
\hline & explicit & 1006.93 & 808.16 & 665.80 & 560.29 & 479.87 & 417.12 & 367.18 & 326.74 & 293.51 & 265.84 \\
\hline & FEM & 1136.60 & 911.25 & 749.82 & 630.19 & 539.03 & 467.93 & 411.32 & 365.48 & 327.85 & 296.49 \\
\hline \multirow{3}{*}{500} & FDM & 1599.41 & 1280.38 & 1051.95 & 882.72 & 753.80 & 653.26 & 573.29 & 508.59 & 455.46 & 411.27 \\
\hline & explicit & 1414.70 & 1133.00 & 931.30 & 781.88 & 668.06 & 579.30 & 508.71 & 451.60 & 404.71 & 365.70 \\
\hline & FEM & 1601.30 & 1281.40 & 1052.20 & 882.51 & 753.23 & 652.47 & 572.30 & 507.45 & 454.22 & 409.94 \\
\hline
\end{tabular}


Table 6. Elastic critical moment for the clamped-clamped beam with the HEA cross-section.

\begin{tabular}{|c|c|c|c|c|c|c|c|c|c|c|c|}
\hline \multirow{2}{*}{$\begin{array}{l}\text { Section } \\
\text { HEA }\end{array}$} & \multirow{2}{*}{ Method } & \multicolumn{10}{|c|}{ Length $[\mathrm{m}]$} \\
\hline & & 4.0 & 4.5 & 5.0 & 5.5 & 6.0 & 6.5 & 7.0 & 7.5 & 8.0 & 8.5 \\
\hline \multirow{3}{*}{140} & FDM & 95.37 & 79.60 & 68.10 & 59.39 & 52.60 & 47.18 & 42.75 & 39.08 & 35.98 & 33.34 \\
\hline & explicit & 85.12 & 71.22 & 61.08 & 53.40 & 47.42 & 42.64 & 38.74 & 35.50 & 32.77 & 30.43 \\
\hline & FEM & 95.32 & 79.54 & 68.03 & 59.32 & 52.53 & 47.10 & 42.68 & 39.00 & 35.91 & 33.27 \\
\hline \multirow{3}{*}{160} & FDM & 162.09 & 134.08 & 113.77 & 98.51 & 86.69 & 77.30 & 69.70 & 63.43 & 58.18 & 53.72 \\
\hline & explicit & 144.28 & 119.57 & 101.66 & 88.20 & 77.78 & 69.51 & 62.81 & 57.29 & 52.66 & 48.73 \\
\hline & FEM & 161.48 & 133.47 & 113.17 & 97.91 & 86.10 & 76.74 & 69.16 & 62.90 & 57.67 & 53.23 \\
\hline \multirow{3}{*}{180} & FDM & 256.10 & 209.40 & 175.75 & 150.63 & 131.33 & 116.13 & 103.90 & 93.90 & 85.58 & 78.58 \\
\hline & explicit & 227.34 & 186.12 & 156.43 & 134.27 & 117.24 & 103.84 & 93.06 & 84.24 & 76.92 & 70.74 \\
\hline & FEM & 255.97 & 209.21 & 175.52 & 150.39 & 131.08 & 115.87 & 103.65 & 93.65 & 85.33 & 78.33 \\
\hline \multirow{3}{*}{200} & FDM & 400.55 & 325.77 & 272.01 & 231.98 & 201.30 & 177.22 & 157.92 & 142.17 & 129.13 & 118.18 \\
\hline & explicit & 355.20 & 289.19 & 241.74 & 206.41 & 179.35 & 158.10 & 141.08 & 127.20 & 115.70 & 106.05 \\
\hline & FEM & 399.57 & 324.71 & 270.92 & 230.88 & 200.21 & 176.13 & 156.85 & 141.14 & 128.11 & 117.19 \\
\hline \multirow{3}{*}{220} & FDM & 630.26 & 509.78 & 423.31 & 359.07 & 309.96 & 271.52 & 240.80 & 215.82 & 195.20 & 177.95 \\
\hline & explicit & 558.36 & 451.99 & 375.66 & 318.95 & 275.62 & 241.69 & 214.59 & 192.56 & 174.37 & 159.16 \\
\hline & FEM & 630.07 & 509.46 & 422.88 & 358.58 & 309.42 & 270.95 & 240.22 & 215.23 & 194.61 & 177.35 \\
\hline \multirow{3}{*}{240} & FDM & 965.48 & 778.82 & 644.97 & 545.61 & 469.73 & 410.40 & 363.06 & 324.62 & 292.93 & 266.46 \\
\hline & explicit & 854.96 & 690.16 & 571.98 & 484.27 & 417.30 & 364.94 & 323.17 & 289.25 & 261.30 & 237.96 \\
\hline & FEM & 965.09 & 778.20 & 644.17 & 544.71 & 468.75 & 409.36 & 362.00 & 323.55 & 291.85 & 265.40 \\
\hline \multirow{3}{*}{260} & FDM & 1371.17 & 1102.25 & 909.56 & 766.66 & 657.68 & 572.57 & 504.77 & 449.81 & 404.59 & 366.89 \\
\hline & explicit & 1213.56 & 976.11 & 805.98 & 679.83 & 583.62 & 508.49 & 448.65 & 400.16 & 360.26 & 327.00 \\
\hline & FEM & 1370.60 & 1101.30 & 908.39 & 765.32 & 656.25 & 571.08 & 503.20 & 448.24 & 402.98 & 365.30 \\
\hline \multirow{3}{*}{280} & FDM & 1898.74 & 1521.27 & 1250.97 & 1050.69 & 898.07 & 779.03 & 684.31 & 607.66 & 544.69 & 492.28 \\
\hline & explicit & 1679.67 & 1346.37 & 1107.70 & 930.86 & 796.12 & 691.03 & 607.42 & 539.76 & 484.19 & 437.94 \\
\hline & FEM & 1898.50 & 1520.60 & 1250.00 & 1049.40 & 896.67 & 777.53 & 682.74 & 606.02 & 543.03 & 490.60 \\
\hline \multirow{3}{*}{300} & FDM & 5 & 22 & 91 & 39 & 12 & 53 & 99 & 85 & 762.04 & 687.78 \\
\hline & explicit & 2375.55 & 1901.69 & 1562.44 & 1311.14 & 1119.72 & 970.48 & 851.79 & 755.79 & 676.98 & 611.44 \\
\hline & FEM & 2686.30 & 2148.70 & 1763.90 & 1479.00 & 1261.80 & 1092.50 & 957.95 & 849.06 & 759.70 & 685.36 \\
\hline \multirow{3}{*}{320} & FDM & 3174.40 & 2540.30 & 2086.31 & 1750.00 & 1493.80 & 1294.04 & 1135.17 & 1006.65 & 901.13 & 813.36 \\
\hline & explicit & 2807.67 & 2247.76 & 1846.90 & 1549.95 & 1323.76 & 1147.40 & 1007.15 & 893.70 & 800.57 & 723.11 \\
\hline & FEM & 3177.20 & 2542.10 & 2087.60 & 1750.60 & 1494.20 & 1294.20 & 1135.10 & 1006.40 & 900.76 & 812.93 \\
\hline
\end{tabular}




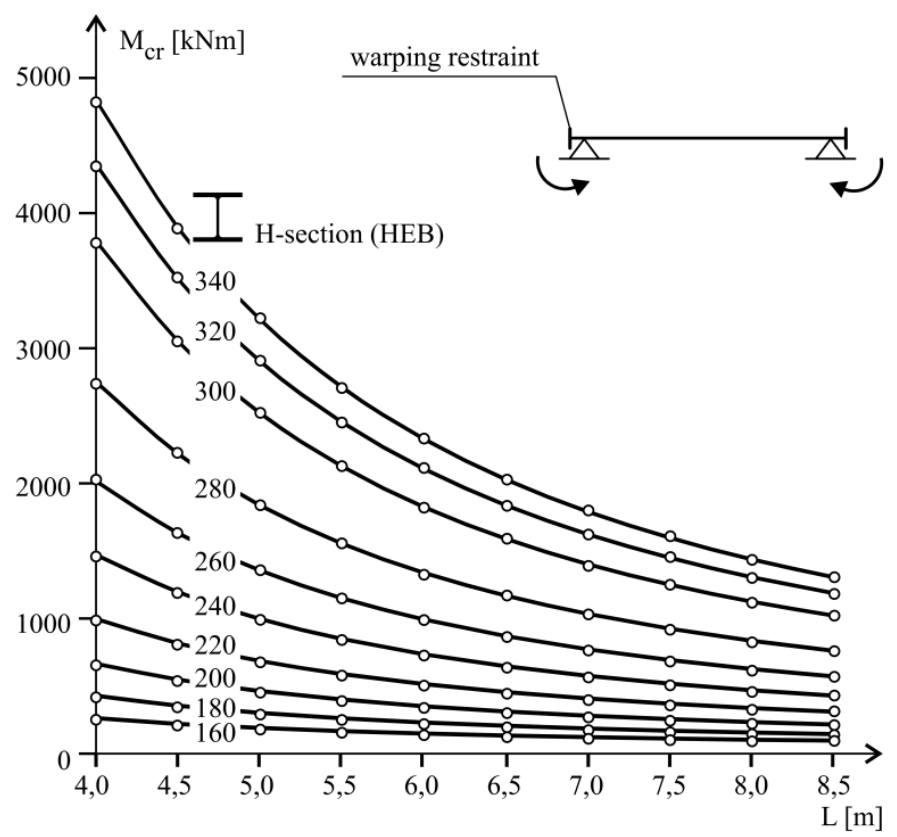

Fig.9. Critical moment versus beam length by the FDM for clamped-clamped beams with the HEB crosssection.

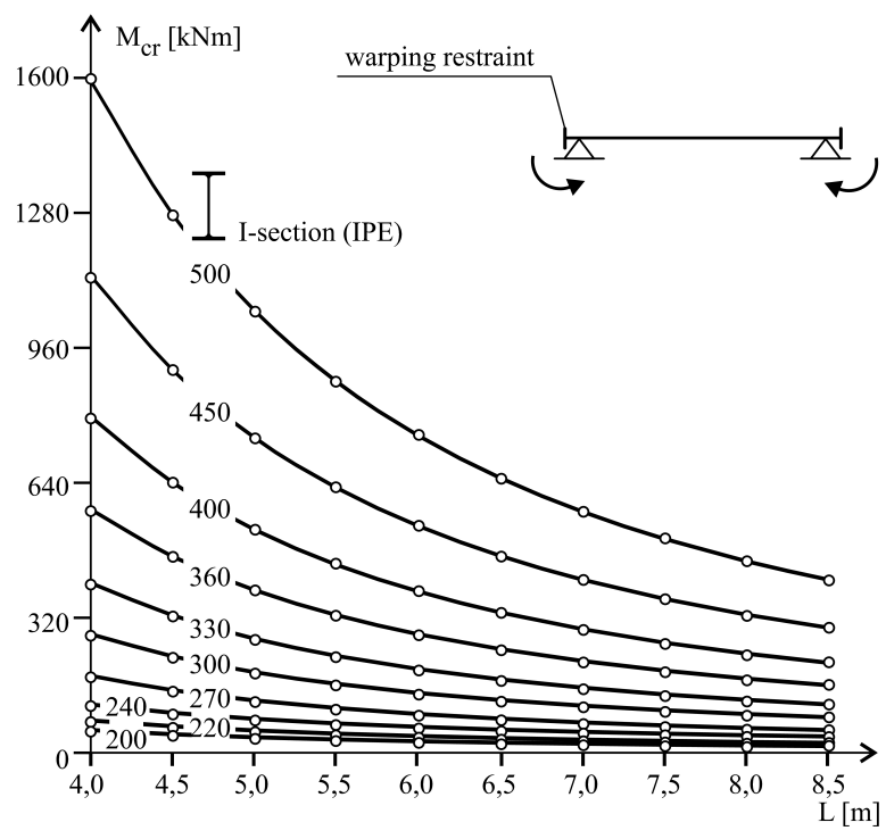

Fig.10. Critical moment versus beam length by the FDM for clamped-clamped beams with the IPE crosssection. 


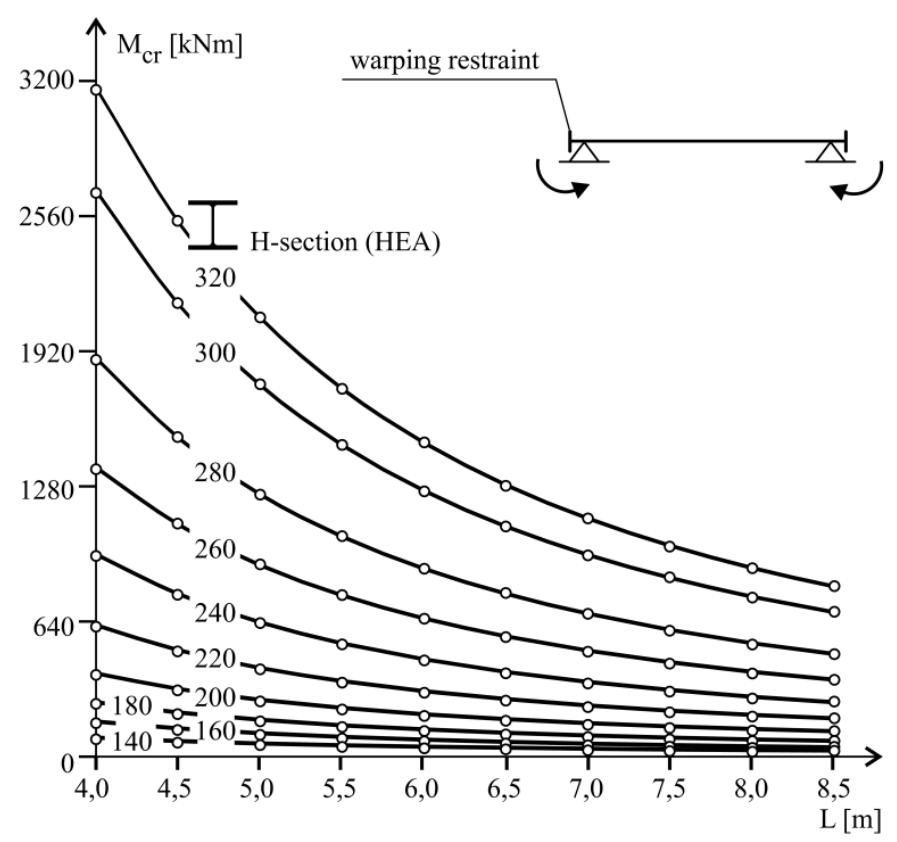

Fig.11. Critical moment versus beam length by the FDM for clamped-clamped beams with the HEA crosssection.

\section{Sensitivity analysis}

Further computational part is entirely devoted to the parameter sensitivity analysis of the critical moment in addition to the length of a beam; the sensitivity coefficients of the critical moment value are determined also for different boundary conditions. The sensitivity coefficient is determined using the central difference approach and then is normalized with respect to the mean values of the varying parameter $L$ and the critical moments $\mathrm{M}_{\mathrm{cr}}(L)$ as Haftka and Gürdal [27]

$$
\frac{d M_{\mathrm{cr}}}{d L}=\frac{\partial M_{\mathrm{cr}}}{\partial L}(L) \cdot \frac{L}{M_{\mathrm{cr}}(L)} \approx \frac{M_{\mathrm{cr}}(L+\Delta L)-M_{\mathrm{cr}}(L+\Delta L)}{2 \Delta L} \cdot \frac{L}{M_{\mathrm{cr}}(L)}
$$

where $\Delta L$ is the assumed increment of the beam length. For the proposed example of the sensitivity coefficients estimation an infinitesimal differences $(\Delta L \rightarrow 0)$ are replaced with the finite increments, to exclude the influence of round-off error for the two compared approximated methods used for critical moment calculation. The finite difference of the length is assumed of constant value for all lengths equal $\Delta L=0.05 \mathrm{~m}$, which accounts for $0.006-0.013$ of the length. The results of numerical analysis provided also in the symbolic algebra system MAPLE are contained in Tab.7 (for the simply supported single bay structure), in Tab.8 (the clamped-clamped beam) as well as in Fig.12 - for both static schemes and, additionally, with $L \in[4.0,8.5]$ meters. We introduce once more two principal design parameters - the profile size (when the length is constant) and the beam length (when the specific profile is to be verified).

We focus on the major HEB profile here and according to the engineering intuition and also after the previous numerical results - all the resulting sensitivity coefficients are negative. It is quantitatively demonstrated here that an increasing of the beam length decreases its critical moment with no doubt. Further, one may observe that the larger the length of the beam, the smaller the sensitivity coefficient under consideration. We may interpret this as the fact that we need to verify the critical moment changes after the length fluctuations or modifications for the relatively short beams - longer single-bay elements are definitely less sensitive to these changes. Quite similarly to the computations made previously, right now all the 
methods coincide almost perfectly for the simply supported beam, while fixing of both supports brings some underestimation in the analytical calculations. The FDM approach, which is the major part of our analysis returns always the largest critical moments and their sensitivity coefficients. Let us note that a very similar sensitivity analysis with respect to the profile size is more difficult, because this size is represented by the discrete values dataset and they are not distributed uniformly. We recall the obvious fact that the larger the size of the profile, the larger the differences in-between geometrical characteristics of the neighboring profiles. This increase is also non-uniform and the differences are un-proportionate and could influence for sure the results of such a central difference approach. Finally, it is seen and especially evident in Fig. 12 that the beam with both ends completely fixed demonstrates each time larger absolute values of the gradients (and hence is more sensitive to the length fluctuations) than the simply supported structure.

Table 7. Sensitivity coefficients of the critical moment for the simply supported beams with the HEB crosssection.

\begin{tabular}{|c|c|c|c|c|c|c|c|c|c|c|c|}
\hline \multirow{2}{*}{\begin{tabular}{|l} 
Section \\
HEB \\
\end{tabular}} & \multirow{2}{*}{ Method } & \multicolumn{10}{|c|}{ Length $[\mathrm{m}]$} \\
\hline & & 4.0 & 4.5 & 5.0 & 5.5 & 6.0 & 6.5 & 7.0 & 7.5 & 8.0 & 8.5 \\
\hline \multirow{3}{*}{160} & FDM & -1.197 & -1.162 & -1.135 & -1.115 & -1.098 & -1.085 & -1.074 & -1.065 & -1.058 & -1.051 \\
\hline & explicit & -1.196 & -1.162 & -1.135 & -1.114 & -1.098 & -1.085 & -1.074 & -1.065 & -1.058 & -1.051 \\
\hline & FEM & -1.197 & -1.160 & -1.135 & -1.111 & -1.100 & -1.087 & -1.076 & -1.058 & -1.054 & -1.050 \\
\hline \multirow{3}{*}{180} & FDM & -1.262 & -1.219 & -1.185 & -1.158 & -1.136 & -1.119 & -1.104 & -1.092 & -1.082 & -1.073 \\
\hline & explicit & -1.262 & -1.219 & -1.185 & -1.158 & -1.136 & -1.118 & -1.104 & -1.092 & -1.081 & -1.073 \\
\hline & FEM & -1.261 & -1.218 & -1.185 & -1.159 & -1.135 & -1.120 & -1.103 & -1.094 & -1.078 & -1.074 \\
\hline \multirow{3}{*}{200} & FDM & -1.316 & -1.267 & -1.228 & -1.196 & -1.170 & -1.149 & -1.131 & -1.116 & -1.103 & -1.093 \\
\hline & explicit & -1.315 & -1.267 & -1.227 & -1.196 & -1.170 & -1.148 & -1.131 & -1.116 & -1.103 & -1.092 \\
\hline & FEM & -1.314 & -1.268 & -1.228 & -1.196 & -1.171 & -1.146 & -1.133 & -1.114 & -1.105 & -1.095 \\
\hline \multirow{3}{*}{220} & FDM & -1.381 & -1.327 & -1.283 & -1.246 & -1.215 & -1.189 & -1.167 & -1.149 & -1.133 & -1.120 \\
\hline & explicit & -1.381 & -1.327 & -1.282 & -1.245 & -1.215 & -1.189 & -1.167 & -1.149 & -1.133 & -1.120 \\
\hline & FEM & -1.381 & -1.328 & -1.282 & -1.242 & -1.215 & -1.195 & -1.169 & -1.150 & -1.134 & -1.121 \\
\hline \multirow{3}{*}{240} & FDM & -1.431 & -1.375 & -1.327 & -1.286 & -1.252 & -1.223 & -1.198 & -1.177 & -1.159 & -1.144 \\
\hline & explicit & -1.431 & -1.374 & -1.326 & -1.286 & -1.252 & -1.223 & -1.198 & -1.177 & -1.159 & -1.143 \\
\hline & FEM & -1.430 & -1.373 & -1.326 & -1.287 & -1.251 & -1.222 & -1.202 & -1.177 & -1.162 & -1.144 \\
\hline \multirow{3}{*}{260} & FDM & -1.494 & -1.435 & -1.384 & -1.340 & -1.302 & -1.270 & -1.241 & -1.217 & -1.196 & -1.178 \\
\hline & explicit & -1.493 & -1.435 & -1.384 & -1.340 & -1.302 & -1.269 & -1.241 & -1.217 & -1.196 & -1.177 \\
\hline & FEM & -1.493 & -1.434 & -1.384 & -1.407 & -1.166 & -1.264 & -1.234 & -1.212 & -1.192 & -1.173 \\
\hline \multirow{3}{*}{280} & FDM & -1.557 & -1.499 & -1.446 & -1.400 & -1.359 & -1.323 & -1.291 & -1.263 & -1.239 & -1.218 \\
\hline & explicit & -1.557 & -1.498 & -1.446 & -1.399 & -1.358 & -1.322 & -1.291 & -1.263 & -1.239 & -1.218 \\
\hline & FEM & -1.547 & -1.490 & -1.440 & -1.392 & -1.352 & -1.317 & -1.286 & -1.260 & -1.236 & -1.214 \\
\hline \multirow{3}{*}{300} & FDM & -1.593 & -1.535 & -1.483 & -1.435 & -1.393 & -1.355 & -1.322 & -1.293 & -1.267 & -1.244 \\
\hline & explicit & -1.593 & -1.535 & -1.482 & -1.435 & -1.393 & -1.355 & -1.322 & -1.293 & -1.267 & -1.244 \\
\hline & FEM & -1.582 & -1.527 & -1.477 & -1.431 & -1.385 & -1.351 & -1.318 & -1.289 & -1.264 & -1.240 \\
\hline \multirow{3}{*}{320} & FDM & -1.595 & -1.537 & -1.485 & -1.437 & -1.395 & -1.357 & -1.324 & -1.295 & -1.268 & -1.245 \\
\hline & explicit & -1.595 & -1.537 & -1.484 & -1.437 & -1.394 & -1.357 & -1.324 & -1.294 & -1.268 & -1.245 \\
\hline & FEM & -1.582 & -1.526 & -1.476 & -1.429 & -1.385 & -1.349 & -1.319 & -1.289 & -1.264 & -1.240 \\
\hline \multirow{3}{*}{340} & FDM & -1.604 & -1.546 & -1.494 & -1.446 & -1.404 & -1.366 & -1.332 & -1.302 & -1.276 & -1.252 \\
\hline & explicit & -1.603 & -1.546 & -1.493 & -1.446 & -1.403 & -1.365 & -1.332 & -1.302 & -1.275 & -1.252 \\
\hline & FEM & -1.592 & -1.537 & -1.483 & -1.440 & -1.396 & -1.358 & -1.326 & -1.295 & -1.271 & -1.247 \\
\hline
\end{tabular}


Table 8 . Sensitivity coefficients of the critical moment for the clamped-clamped beams with the HEB crosssection.

\begin{tabular}{|c|c|c|c|c|c|c|c|c|c|c|c|}
\hline \multirow{2}{*}{\begin{tabular}{|l|} 
Section \\
HEB \\
\end{tabular}} & \multirow{2}{*}{ Method } & \multicolumn{10}{|c|}{ Length [m] } \\
\hline & & 4.0 & 4.5 & 5.0 & 5.5 & 6.0 & 6.5 & 7.0 & 7.5 & 8.0 & 8.5 \\
\hline \multirow{3}{*}{160} & FDM & -1.545 & -1.485 & -1.433 & -1.390 & -1.352 & -1.320 & -1.292 & -1.268 & -1.248 & -1.230 \\
\hline & explicit & -1.494 & -1.436 & -1.385 & -1.341 & -1.303 & -1.270 & -1.242 & -1.217 & -1.196 & -1.178 \\
\hline & FEM & -1.519 & -1.462 & -1.416 & -1.374 & -1.334 & -1.310 & -1.280 & -1.259 & -1.241 & -1.221 \\
\hline \multirow{3}{*}{180} & FDM & -1.636 & -1.575 & -1.521 & -1.474 & -1.432 & -1.395 & -1.363 & -1.335 & -1.310 & -1.288 \\
\hline & explicit & -1.587 & -1.529 & -1.476 & -1.429 & -1.387 & -1.349 & -1.316 & -1.287 & -1.262 & -1.239 \\
\hline & FEM & -1.604 & -1.547 & -1.498 & -1.455 & -1.415 & -1.384 & -1.348 & -1.318 & -1.297 & -1.274 \\
\hline \multirow{3}{*}{200} & FDM & -1.696 & -1.638 & -1.584 & -1.536 & -1.493 & -1.454 & -1.419 & -1.388 & -1.360 & -1.335 \\
\hline & explicit & -1.648 & -1.593 & -1.541 & -1.493 & -1.450 & -1.411 & -1.375 & -1.343 & -1.315 & -1.289 \\
\hline & FEM & -1.663 & -1.608 & -1.558 & -1.515 & -1.475 & -1.444 & -1.407 & -1.378 & -1.348 & -1.324 \\
\hline \multirow{3}{*}{220} & FDM & -1.759 & -1.705 & -1.654 & -1.606 & -1.562 & -1.522 & -1.486 & -1.452 & -1.422 & -1.395 \\
\hline & explicit & -1.711 & -1.660 & -1.612 & -1.565 & -1.522 & -1.482 & -1.445 & -1.412 & -1.381 & -1.352 \\
\hline & FEM & -1.721 & -1.673 & -1.625 & -1.582 & -1.542 & -1.506 & -1.468 & -1.442 & -1.405 & -1.382 \\
\hline \multirow{3}{*}{240} & FDM & -1.800 & -1.749 & -1.701 & -1.655 & -1.612 & -1.572 & -1.535 & -1.501 & -1.470 & -1.440 \\
\hline & explicit & -1.752 & -1.705 & -1.660 & -1.616 & -1.574 & -1.534 & -1.497 & -1.463 & -1.431 & -1.401 \\
\hline & FEM & -1.760 & -1.715 & -1.671 & -1.630 & -1.589 & -1.555 & -1.519 & -1.485 & -1.455 & -1.429 \\
\hline \multirow{3}{*}{260} & FDM & -1.844 & -1.798 & -1.754 & -1.712 & -1.671 & -1.632 & -1.596 & -1.561 & -1.529 & -1.500 \\
\hline & explicit & -1.796 & -1.755 & -1.714 & -1.673 & -1.634 & -1.596 & -1.560 & -1.525 & -1.493 & -1.463 \\
\hline & FEM & -1.802 & -1.767 & -1.727 & -1.681 & -1.649 & -1.615 & -1.579 & -1.548 & -1.519 & -1.484 \\
\hline \multirow{3}{*}{280} & FDM & -1.883 & -1.843 & -1.803 & -1.764 & -1.727 & -1.690 & -1.655 & -1.622 & -1.590 & -1.561 \\
\hline & explicit & -1.834 & -1.799 & -1.763 & -1.727 & -1.691 & -1.655 & -1.621 & -1.588 & -1.557 & -1.527 \\
\hline & FEM & -1.840 & -1.806 & -1.775 & -1.735 & -1.704 & -1.666 & -1.638 & -1.606 & -1.578 & -1.546 \\
\hline \multirow{3}{*}{300} & FDM & -1.902 & -1.865 & -1.828 & -1.792 & -1.756 & -1.722 & -1.688 & -1.656 & -1.625 & -1.596 \\
\hline & explicit & -1.854 & -1.822 & -1.788 & -1.755 & -1.721 & -1.688 & -1.655 & -1.623 & -1.592 & -1.563 \\
\hline & FEM & -1.859 & -1.825 & -1.796 & -1.763 & -1.733 & -1.704 & -1.668 & -1.646 & -1.612 & -1.582 \\
\hline \multirow{3}{*}{320} & FDM & -1.903 & -1.866 & -1.830 & -1.794 & -1.758 & -1.724 & -1.690 & -1.658 & -1.627 & -1.597 \\
\hline & explicit & -1.855 & -1.823 & -1.790 & -1.756 & -1.723 & -1.690 & -1.657 & -1.625 & -1.594 & -1.565 \\
\hline & FEM & -1.859 & -1.828 & -1.797 & -1.766 & -1.734 & -1.697 & -1.670 & -1.644 & -1.617 & -1.584 \\
\hline \multirow{3}{*}{340} & FDM & -1.908 & -1.871 & -1.836 & -1.800 & -1.765 & -1.731 & -1.698 & -1.666 & -1.635 & -1.606 \\
\hline & explicit & -1.859 & -1.828 & -1.796 & -1.763 & -1.730 & -1.697 & -1.665 & -1.634 & -1.603 & -1.574 \\
\hline & FEM & -1.863 & -1.833 & -1.799 & -1.771 & -1.739 & -1.708 & -1.677 & -1.651 & -1.620 & -1.593 \\
\hline
\end{tabular}




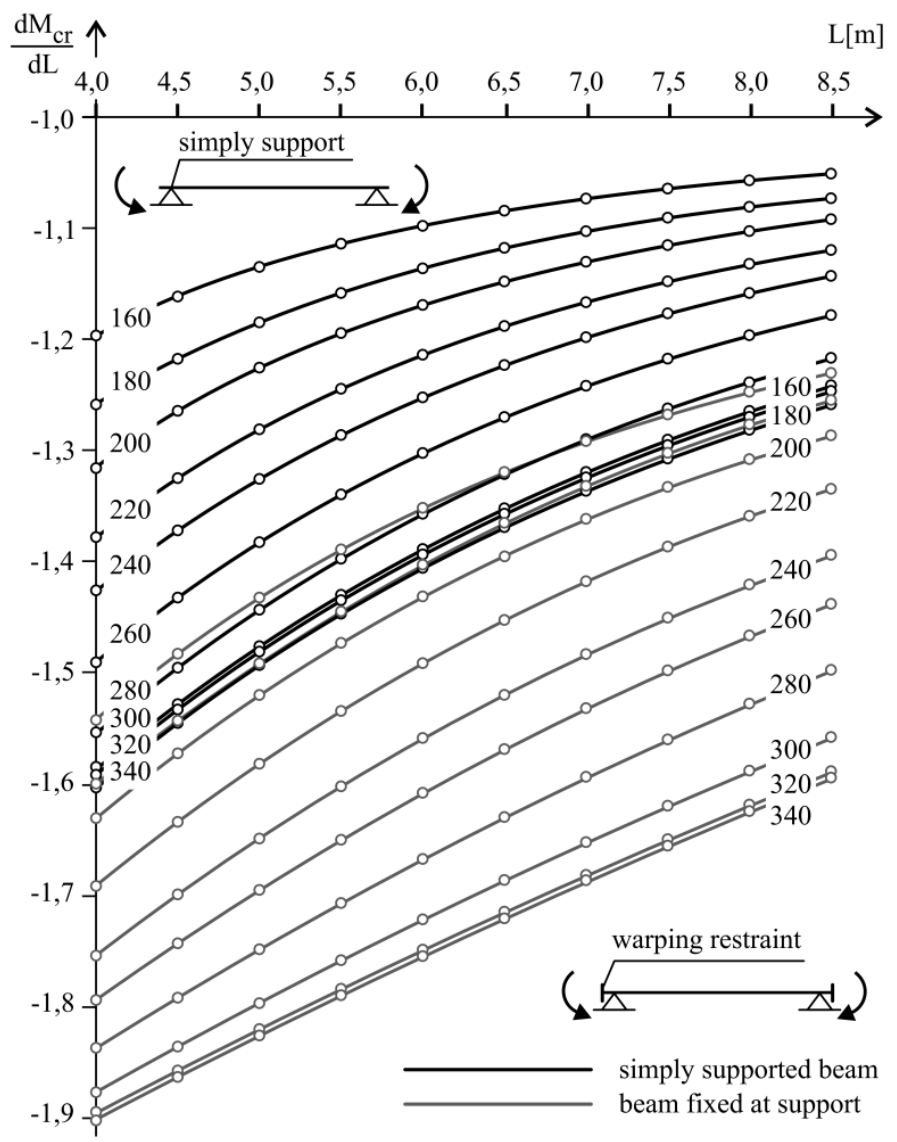

Fig.12. Sensitivity coefficients of the critical moment according to the FDM for the HEB cross-sections.

\section{Conclusions}

The most important conclusion coming from computational analysis carried out and documented in this paper is very good agreement of all the techniques available, i.e., analytical, Finite Difference and Finite Element Methods, for a determination of the critical moment in the thin walled single-bay steel beams in the elastic regime. It is especially apparent for the simply supported structures that dominate civil engineering applications, but it looks also promising for the elements fully clamped at both ends. Furthermore, this satisfactory agreement is noticed for the sensitivity coefficients of the critical moments in addition to the beam length, which is one of the most frequent design parameters in steel structures. It needs to be mentioned that this analysis is demonstrated for a variety of the steel profiles belonging to the families of HEB, HEA and IPE profiles, where the first group brings quite naturally the largest capacity from the critical moment point of view. Multiple difference in-between the results obtained for the HEB and IPE shows that it is impossible to simply replace these profiles with each other during structural design. Analytical method brings here the less optimistic results for the critical moments, so that the safety margin is the largest one for the engineers employing simple Eurocode formula to design the steel beams. Almost a perfect agreement inbetween all the methods applied brings the opportunity to create their own software consistent with the Finite Difference Method, which is a very easy task for the regular straight geometry and regular grid.

There is no doubt that this problem deserves further attention as well as some new concepts especially in the elasto-plastic range dominating the loss of stability for thicker profiles (class I and II according to the Eurocodes statements (ENV 1993-1-1:1992 Eurocode 3 [25]) considering mathematical complexity of the initial differential equation governing critical moment phenomenon. One needs to analyze mono-symmetric profiles also, these without any in-plane symmetry axis, where the governing equations is 
more complex as well as the beams with varying web height and the very popular recently plate girders with the sinusoidal webs, where the center line is also of the sinusoidal shape in the longitudinal direction of the element. Even the elastic range still has unsolved problems of the curvilinear and/or multi-bay girders and, structural sensitivity with other geometrical and/or material parameters. Further theoretical and computational studies will make it possible to investigate both qualitatively and quantitatively a coincidence between fatigue of the structural steel and particular structures subjected to it with their critical moments, that can be of the paramount importance in bridge girders, for instance. Separate interest is associated with the torsional-bending stability including randomness in local thickness variations according to corrosion as well as stochastic structural imperfections in steel structures (Melchers [28]) to be incorporated into the numerical analysis by the application of the Stochastic perturbation-based Finite Element (or Finite Difference) Method (Nayfeh [29], Kamiński [30]) implemented thanks to the Least Squares Method (Björck [31]), for instance.

\section{Nomenclature}

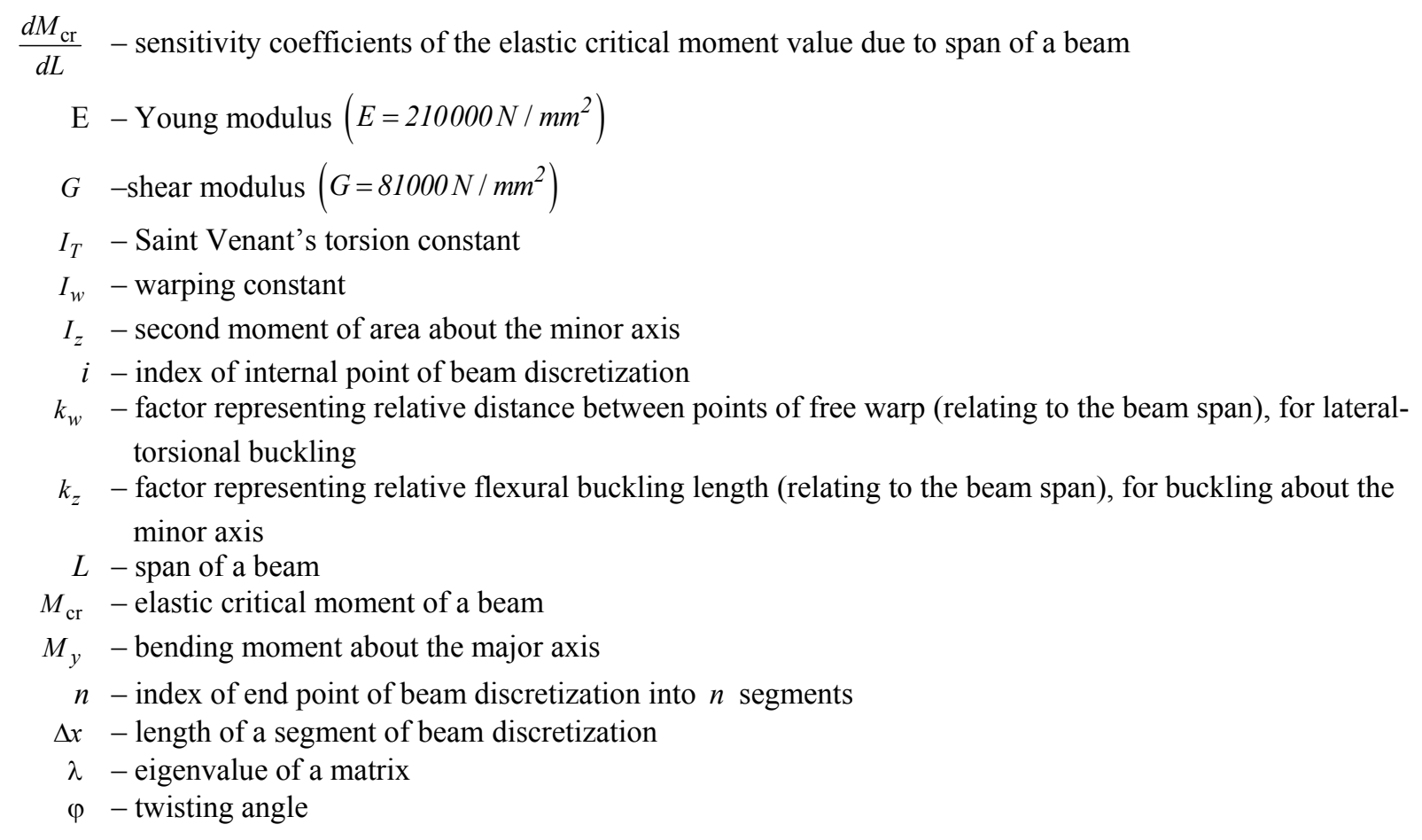

\section{References}

[1] Trahair N.S. (1993): Flexural-Torsional Buckling of Structures. - London, E\&FN SPON.

[2] Trahair N.S. (1996): Laterally unsupported beams. - Engineering Structures, vol.18, pp.759-768.

[3] Bleich F. (1952): Buckling Strength of Metal Structures. - New York: McGraw-Hill.

[4] Chen W.F. and Atsuta T. (1977): Theory of Beam-Columns. - Space Behavior and Design, vol.2. New York, McGraw-Hill.

[5] Galambos T.V. (1998): Guide to Stability Design Criteria for Metal Structures. - 5th ed., Wiley.

[6] Timoshenko S.P. and Gere J.M. (1961): Theory of Elastic Stability. - 2nd ed. New York: McGraw-Hill.

[7] Vlasov V.Z. (1961): Thin-walled Elastic Beams. - 2nd ed., Jerusalem, Israel, Israel Program for Scientific Translation. 
[8] Lam C.C., Yam M.C.H., Iu V.P. and Cheng J.J.R. (2000): Design for lateral torsional buckling of coped I-beams. Journal of Constructional Steel Research, vol.54, pp.423-443.

[9] Masarira A. (2002): The effect of joints on the stability behaviour of steel frame beams. - Journal of Constructional Steel Research, vol.58, pp.1375-1390.

[10] Tong G.S., Yan X.X. and Zhang L. (2005): Warping and bimoment transmission through diagonally stiffened beam-to-column joints. - Journal of Constructional Steel Research, vol.61, pp.749-763.

[11] Larue B., Khelil A. and Gueury M. (2007): Elastic flexural-torsional buckling of steel beams with rigid and continuous lateral restraints. - Journal of Constructional Steel Research, vol.63, pp.692-708.

[12] SN003a-EN-EU - NCCI: Elastic critical moment for lateral torsional buckling.

[13] Serna M.A., López A., Puente I. and Yong D.J. (2006): Equivalent uniform moment factors for lateral-torsional buckling of steel members. - Journal of Constructional Steel Research, vol.62, pp.566-580.

[14] Nguyen C.T., Moon J., Le V.N. and Lee H.E. (2010): Lateral torsional buckling of I-girders with discrete torsional bracings. - Journal of Constructional Steel Research, vol.66, pp.170-177.

[15] Nguyen C.T., Joo H.S., Moon J. and Lee H.E. (2012): Flexural-torsional buckling strength of I-girders with discrete torsional braces under various loading conditions. - Engineering Structures, vol.36, pp.337-350.

[16] Park J.S., Stallings J.M. and Kang Y.J. (2004): Lateral-torsional buckling of prismatic beams with continuous topflange bracing. - Journal of Constructional Steel Research, vol.60, pp.147-160.

[17] Bathe K.J. (1996): Finite Element Procedures. - Prentice Hall, Englewood Cliffs.

[18] Zienkiewicz O.C. and Taylor R.L. (2005): Finite Element Method for Solid and Structural Mechanics. - 6th edition, Amsterdam: Elsevier.

[19] Liszka T. and Orkisz J. (1980): The finite difference method at arbitrary irregular grids and its applications in applied mechanics. - Computers and Structures, vol.11, pp.83-95.

[20] Mitchell A.R. and Griffiths D.F. (1980): The Finite Difference Method in Partial Differential Equations. Chichester: Wiley.

[21] Wasow W.R. and Forsythe G.E. (1959): Finite Difference Methods for Partial Differential Equations. - New York-London: Wiley.

[22] Char B.W. (1992): First Leaves: A Tutorial Introduction to Maple V. - Berlin-Heidelberg: Springer-Verlag.

[23] Zhang L. and Tong G.S. (2008): Elastic flexural-torsional buckling of thin-walled cantilevers. - Thin-Walled Structures, vol.46, pp.27-37.

[24] Suryoatmono B. and Ho D. (2002): The moment-gradient factor in lateral-torsional buckling on wide flange steel sections. - Journal of Constructional Steel Research, vol.58, pp.1247-1264.

[25] ENV 1993-1-1:1992 Eurocode 3 - Design of steel structures - Part 1-1: General rules - General rules and rules for building.

[26] Kamiński M. (2009): A generalized stochastic finite difference method. - Journal of Theoretical and Applied Mechanics, vol.47, pp.957-975.

[27] Haftka R.T. and Gürdal Z. (1992): Elements of Structural Optimization. - Amsterdam: Kluwer Acad. Publ.

[28] Melchers R.E. (2002): Structural Reliability Analysis and Prediction. - Chichester: Wiley.

[29] Nayfeh A. (1973): Perturbation Methods. - New York: Wiley.

[30] Kamiński M. (2013): The Stochastic Perturbation Method for Computational Mechanics. - Chichester: Wiley.

[31] Björck A. (1996): Numerical Methods for Least Squares Problems. - SIAM, Philadelphia.

Received: June 12, 2015

Revised: December 21, 2015 